\title{
Comprensión del territorio para la construcción de apropiación e identidad en el municipio de Soacha
}

\author{
Understanding the territory for the construction of appropriation and identity in the Municipality of \\ Soacha
}

\author{
Andrea Bibiana Reyes-Guarnizo \\ Universidad La Gran Colombia. Bogotá (Colombia) \\ Facultad de Arquitectura, Programa de Arquitectura
}

Reyes-Guarnizo, A. (2020). Comprensión del territorio para la cons trucción de apropiación e identidad en el Municipio de Soacha. Revista de Arquitectura (Bogotá), 22(I). 44-57. http://dx.doi. org/l0.147I8/RevArq.2020.265I
Arquitecta, Universidad Piloto de Colombia. Bogotá (Colombia).

Especialista en gestión ambiental urbana, Universidad Piloto de Colombia. Bogotá (Colombia). Magíster en educación, Pontificia Universidad Javeriana, Bogotá (Colombia).

https://scholar.google.com.co/citations?user $=$ Tmco2hMAAAAJ\&hl=es

(D) https://orcid.org/0000-0002-0434-8464 andrea.reyes@ugc.edu.c

\section{Resumen}

El crecimiento demográfico del municipio de Soacha (Colombia) genera un impacto urbano y ecológico que propicia la disminución del sentido de pertenencia y de arraigo entre sus habitantes; por ello, se busca reconocer cuáles son las experiencias que los diferentes actores involucrados tienen sobre el municipio. La presente investigación tiene un enfoque cualitativo, donde se analizan los Planes Nacionales de Desarrollo (PND) entre 1970 y 2012 , a la luz del crecimiento urbano, las características históricas y las políticas de gobierno. Se aplicaron encuestas y ejercicios de cartografía social, con lo que se evidenciaron los contrastes entre las percepciones del municipio por parte de sus habitantes, caracterizadas por la indiferencia hacia lo público y la agresividad hacia el medio ambiente. Se trabajó con un grupo focal a través de una estrategia de reconocimiento del territorio. El resultado permitió analizar cómo la construcción del territorio depende de la interacción de los grupos sociales con el entorno físico; de esta manera, se construyen relaciones de apropiación que realzan rasgos identitarios, y ello es fundamental para fomentar un cambio en la percepción de dichos grupos sobre el municipio y suscitar interés en continuar reconociendo el territorio.

Palabras clave: crecimiento urbano; desarrollo urbano; imaginarios urbanos; percepción urbana; políticas públicas; segregación urbana.

\begin{abstract}
The demographic growth of the municipality of Soacha (Colombia) generates an urban and ecological impact that leads to a decrease in the sense of belonging and roots among its inhabitants. Therefore, it was sought to identify the perceptions that the different actors involved had about the municipality. This research had a qualitative approach, where the National Development Plans (PND, for its Spanish acronym) between 1970 and 2012 were analyzed, in the light of urban growth, historical characteristics and government policies. Surveys and social mapping exercises were applied, which evidenced the contrasts between the perceptions of the inhabitants about the municipality, characterized by indifference towards the public sphere and aggressiveness towards the environment. The project worked with a focus group through a territory recognition strategy. The result allowed to analyze how the construction of the territory depends on the interaction of social groups with the physical environment. In this way, appropriation relationships that enhance identity traits are built, and this is essential to foster a change in the perception of those groups about the municipality and arouse interest in continuing to recognize the territory.
\end{abstract}

Keywords: Urban growth; urban development; urban imaginary; urban perception; public politics; urban segregation.

\section{Introducción}

El presente artículo hace parte de los resultados de la investigación Valoración e influencia del proceso de urbanización en Soacha entre 19702012. El marco conceptual de este proyecto considera tanto los imaginarios colectivos como la apropiación del territorio dentro del recorrido que se hace sobre las transformaciones urbanas del municipio de Soacha, del departamento de Cundinamarca, en Colombia. El proyecto de investigación, trabajo que se desarrolló desde 2012, se inscribe en el grupo de Diseño y Gestión del Hábitat Territorial, de la Universidad La Gran Colombia. Este proceso investigativo contó con la asesoría técnica de la Corporación Ambiental Caminando el Territorio, con quienes se desarrollaron talleres comunitarios.

Soacha es uno de los municipios con mayor densidad poblacional en el departamento de Cundinamarca, con un crecimiento demográfico acelerado.

[...] la tasa de crecimiento poblacional intercensual fue de $9,77 \%$ entre $1973-1985 ; 8,58 \%$ entre $1985-1993$ y de $3,7 \%$ entre $1993-2003$. El crecimiento de la cabecera en los respectivos períodos fue $13,1 \%, 9,4 \%$ y $3,9 \%$ [...] El crecimiento de Soacha ha llevado a una urbanización caótica en la que la provisión de servicios públicos y la planificación urbana se dificultan. Esta situación se agrava debido a la proliferación de urbanizadores piratas y al bajo desarrollo político del municipio. (Cámara de Comercio de Bogotá, 2005)

Tanto el crecimiento demográfico como el urbano afectan el sentido de pertenencia, por cuanto no existen una cultura ciudadana ni una política que lo incentiven. Soacha tiene una 
población nativa de solo el 14,6\% ${ }^{1}$. La falta de arraigo cultural de la población del municipio se refleja en el comportamiento ciudadano, el cual se caracteriza por la indiferencia hacia lo público, la agresividad hacia el medio ambiente y el desarrollo de actividades principalmente sociales, laborales y formativas fuera del municipio (Reyes Guarnizo, 2011).

Así mismo, el diagnóstico que presenta Plan de Desarrollo Municipal-Soacha para vivir mejor (Acuerdo 18 de 2008) señala que:

\section{[...] la desinstitucionalización del municipio expli- cado por la baja presencia del Estado y de los actores privados y comunitarios en todo el terri- torio, sumado a las dinámicas históricas de ocupa- ción y alto crecimiento poblacional desordenado han configurado a Soacha como un municipio que aún no se consolida como una verdadera ciu- dad que cubra las demandas de sus ciudadanos y ciudadanas. (p. 9)}

Por otra parte, el escenario urbano es complejo, y tal situación no solo se alimenta con la publicidad que presentan los medios de comunicación en lo que respecta a los nuevos proyectos de vivienda, y que desvirtúan el lugar real en el que estos se desarrollan, pues

[...] la vecindad con el Distrito Capital, asociado a la enorme presión que se ejerce en el territorio por la demanda de suelos, ha generado un proceso de conurbación en donde el límite o lindero políticoadministrativo, está reflejado en los planos, ya que físicamente no existe ninguna separación de infraestructura de servicios y mucho menos aun en uso y ocupación del suelo fronterizo. (Acuerdo 46 de 2000, p. 1)

\section{Los imaginarios urbanos y la apropiación del territorio. Un recorrido conceptual}

Los dos conceptos clave dentro de la investigación son los imaginarios urbanos y la apropiación del territorio. El concepto de imaginarios colectivos se contempla, principalmente, desde las construcciones que sobre él han hecho diferentes autores; entre ellos, Néstor García Canclini (2005), Abilio Vergara Figueroa (2001), Gilbert Durand $(1964 ; 1994)$ y Daniel Hiernaux (2007), entre otros.

Para comenzar, Torres (2010) plantea que la idea central de los imaginarios radica, sobre todo, en la fabricación de una imagen visible y en la abstracción de un símbolo (significado-significante) de los actores sociales urbanos que se encuentran en un espacio determinado. A su vez, Gilbert Durand (1994), citado por Hiernaux 2007), define el imaginario como:

[...] la inevitable representación, la facultad de la simbolización de la cual emergen continuamente todos los miedos, todas las esperanzas y sus frutos culturales desde hace aproximadamente un millón y medio de años, cuando el homo erecto se levantó sobre la tierra. (p. 77)

1 Según datos del censo experimental del Soacha, realizado en 2003, citado por la Cámara de Comercio de Bogotá (2005).
Así mismo, tanto Vergara Figueroa (2001) como Torres (2010), arquitectos mexicanos, consideran que la construcción conceptual de lo imaginario se contempla desde todo lo que se estructura a partir de lo real y de las prácticas sociales. Lo imaginario es la construcción de la representación social y cultural, tanto individual como colectiva, de una práctica sociocultural en un determinado espacio, donde lo simbólico se relaciona con la producción social de un tipo de cultura, y que, a partir de la interacción, los significados y los símbolos, permean una territorialidad dada. Por tanto, las imágenes mentales que cada persona produce se hacen colectivas en tanto estas se comunican en un grupo social.

Además, Torres (2010) plantea que la idea central de los imaginarios radica, principalmente, en la fabricación de una imagen visible y la abstracción de un símbolo (significado-significante) de los actores sociales urbanos que se encuentran en un espacio determinado.

Gilbert Durand (1964), citado por Hiernaux (2007), destaca la importancia del tema de los imaginarios y lo simbólico, con la perspectiva de generar una nueva pedagogía del conocimiento particularmente útil para los estudios urbanos. Al respecto, expresa que,

[El] conocimiento simbólico definido de manera triple como pensamiento por siempre indirecto, como presencia figurada de la trascendencia y como comprensión epifánica, parece estar en las antípodas de la pedagogía del saber tal como se ha ido instituyendo en occidente desde hace diez siglos. (p. 22)

Por su parte, Néstor García Canclini (2005) plantea que:

\footnotetext{
[...] muchos presupuestos que guían la acción y las omisiones de los ciudadanos derivan de cómo percibimos los usos del espacio urbano, los problemas de consumo, tránsito y comunicación, y también de cómo imaginamos las explicaciones a estas cuestiones. (p. 47)
}

Se puede decir que en la formación del imaginario se ubica la percepción transformada en representaciones a través de la imaginación; así mismo, aporta un elemento de sentido a las representaciones y las trasformaciones simbólicas. Siguiendo a Hiernaux (2007), la imaginación trabaja intensamente en ese andar que va de la percepción original del entorno visual a la construcción de un imaginario que se enfrenta a la existencia de imágenes anteriores que tejen, por complementariedad o bien por oposición, el imaginario del espacio de referencia.

En relación con el concepto de apropiación del territorio, se parte de la conceptualización de territorio dentro de su construcción social, para lo cual también se abordarán los temas de espacio simbólico, identidad y apego al lugar.

La palabra territorio se deriva del latín territorium, y significa extensión de tierra dividida políticamente. Sus componentes léxicos son térra 


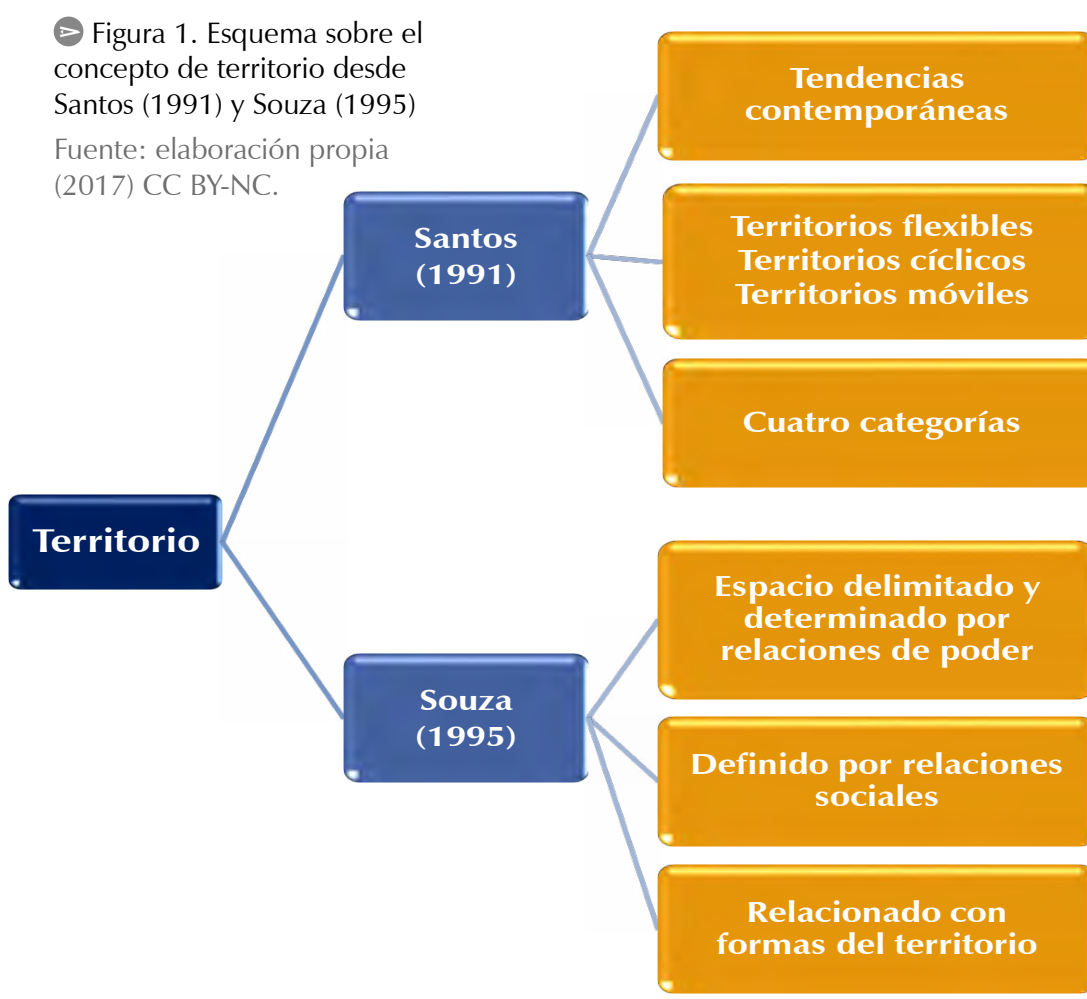

Expansión imposición - Procesos de mundialización

Homogenización de las costumbres y los usos - Globalización

1. Forma: Visible - patrón espacial

2. Función: Tarea $o$ actividad de la forma

3. Estructura: - Aspectos sociales y económicos

4. Proceso: Acción frecuente continua - paisaje - lugar - región - territorio
2. Culturales: Asociación de barrios - apropiación

3. Económicas: Empresa - recursos (tierra) más el sufijo orio (pertenencia, lugar), que conjuntamente significan, según Lobato Correa, (1997) citado por Montañez (2001), la tierra que pertenece.

Es así como el concepto de territorio denota aspectos relacionales que proponen vínculos de dominio, de poder, de pertenencia o de apropiación entre una porción o la totalidad del espacio geográfico con un determinado sujeto individual o colectivo. De igual manera, Schneider y Peyre (2006) hacen un recorrido conceptual desde los enfoques de diferentes autores, quienes presentan varios aportes al concepto de territorio e introducen el concepto de desterritorialización ${ }^{2}$. En la figura 1 se presenta un esquema con los aportes que hacen Santos (1991) y Souza (1995).

También se puede definir el territorio como el espacio geográfico ${ }^{3}$ revestido de las dimensiones política, identitaria y afectiva. Santos (1997), citado por Montañez (2001), define el espacio geográfico como conjunto indisociable, solidario y contradictorio, donde operan dos sistemas: el sistema objeto y el sistema acciones (figura 2).

El lugar como concepto (figura 3), se constituye en punto de referencia para la comprensión del territorio desde el espacio apropiado, ya que desde aquí posibilita la referencia simbólica y de identidad; por otra parte, el concepto de lugar

2 Desde los aportes de Rogelio Haesbaert (1997, 2002, 2004a, 2004b), se plantean la desterritorialización y la desculturación como una dinámica en paralelo con el proceso de territorialización, a pesar de la lucha de identidad que se da en algunos lugares. De igual manera, esta dinámica se relaciona con la comprensión del territorio desde las redes de información, que presentan Sposito, Saquet y Ribas (2004). Cabe anotar que estos autores son, igualmente, citados en el trabajo de Schneider y Peyre (2006).

3 Montañez (2001) define el espacio geográfico como categoría social e histórica, categoría de procesos y resultados, las cuales son entendidas como: producción, apropiación, integración, apropiación social y relaciones espaciales. como espacio dominado, se relaciona con el poder donde se configuran relaciones cerradas en la mayoría de los casos.

Ahora bien, el concepto de apropiación se considera a partir su dualidad; es decir: por un lado, desde la acción-trasformación, la cual entronca con la territorialidad y el espacio personal, como lo anotan Vidal Montana y Pol Urrutia (2005) sobre el texto de Irvin Altman (1975); por otro, desde la identificación simbólica, la cual se vincula con los procesos afectivos, cognitivos e interactivos.

Frente a la acción-transformación, el análisis histórico que presenta Néstor García Canclini (1995) permite comprender cómo los procesos de territorialidad hoy en día son propiciados, generalmente, por el Estado, que, en alianza con algunos grupos y en aras del desarrollo, orienta las dinámicas de las ciudades, aunque bien partieron de una apuesta por la ciudadanía al decir que "la ciudadanía estuvo asociada a la capacidad de apropiarse de los bienes y al modo de usarlos" (p. 13).

Desde perspectivas políticas que relacionan a las comunidades, no necesariamente se consideraron desde la identificación simbólica los procesos de territorialidad que involucran el fenómeno de la apropiación del espacio que admiten una forma de comprender y explicar la manera como se generan las relaciones que las personas mantienen con los espacios desde tres posibilidades de vínculo: consigo mismo, con los otros y con el entorno.

Es importante rescatar que los autores citados hasta ahora coinciden en la necesidad de trascender del espacio al lugar, a fin de lograr la identidad, el apego, el reconocimiento simbólico de los espacios en el trascurrir de la historia y la apropiación del espacio urbano desde una propuesta teórica que permita abordar temas como la construcción social del espacio público, 


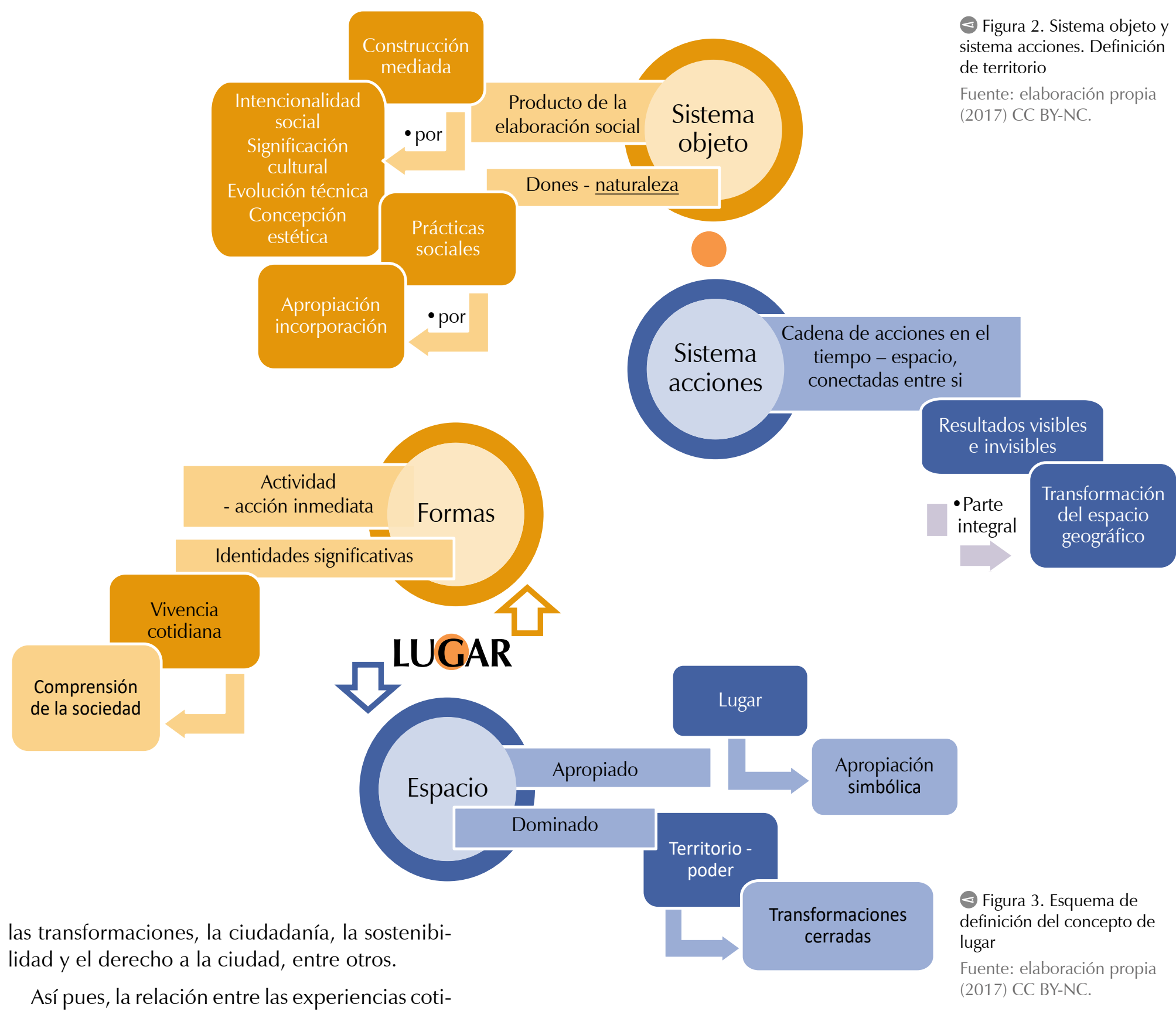

dianas y las acciones, las emociones, las pautas y las nociones que se tienen del lugar cambian, se construyen y se reconstruyen constantemente.

\section{Metodología}

El enfoque de la presente investigación es cualitativo, dado que este método

\begin{abstract}
[...] busca conceptuar sobre la realidad teniendo presente comportamientos, conocimientos, actitudes y valores que guían la conducta de las personas estudiadas. El proceso de investigación cualitativa explora de manera sistemática los conocimientos y valores que comparten los individuos en un determinado contexto espacial y temporal. (Bonilla Castro \& Rodríguez Sehk, 1997)
\end{abstract}

Para esta investigación se utilizaron las siguientes técnicas de recolección de información: revisión documental, entrevistas, encuestas y un ejercicio básico de cartografía social. Todas ellas fueron organizadas en dos fases. La primera, relacionada con la revisión documental, considera los PND ${ }^{4}$ entre 1970 y 2012 de cara al pro-

4 Los PND son instrumentos de gestión que plantean los lineamientos para la promoción de un territorio. Son elaborados por las autoridades estatales y determinan las políticas, las estrategias y las acciones frente al tiempo de mandato. ceso de crecimiento y transformación urbana del municipio. En la variable Apropiación del territorio se abordan las características históricas y las políticas de gobierno desde los PND relacionadas con la identidad simbólica.

La segunda fase versa sobre la aplicación de instrumentos que se analizan desde la categoría de los imaginarios urbanos y los procesos de apropiación y apego al lugar. La variable Imaginarios urbanos se presenta desde una mirada territorial señalando las trasformaciones tanto de lo urbano como de lo ambiental en el municipio de Soacha.

$\mathrm{Al}$ indagar sobre los imaginarios del municipio, previamente se buscó en fuentes tanto primarias como secundarias sobre las principales palabras que pudieran dar cuenta del imaginario que tienen las personas sobre el municipio.

La encuesta estuvo estructurada en cinco partes. En la primera se relacionó información general de la persona encuestada. En la segunda se preguntó por la situación habitacional refiriéndose a la tenencia del inmueble, para considerar si la vivienda es propia y las razones que llevaron a 

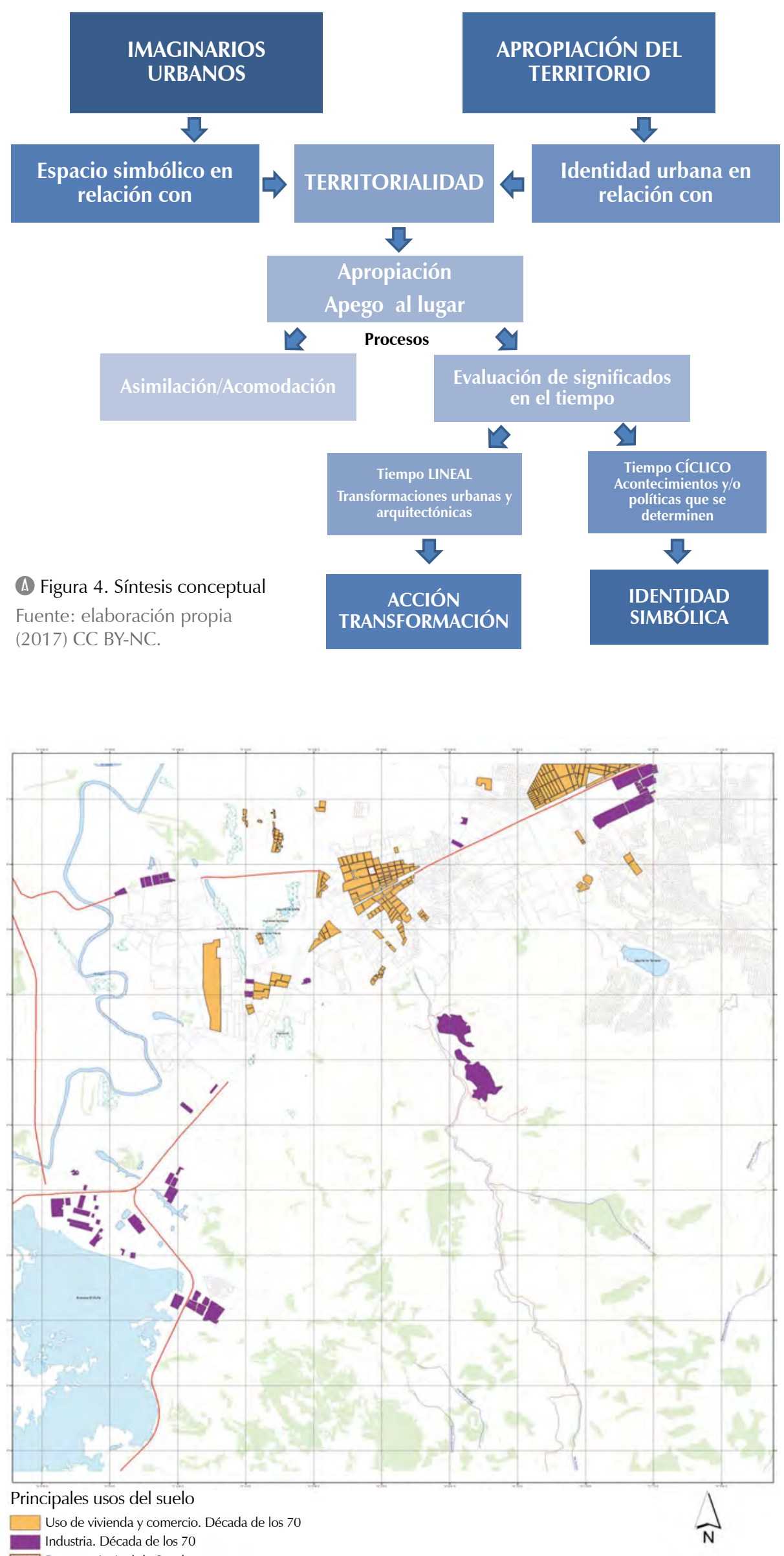

da de $\operatorname{los} 70$

la persona a comprar en el municipio; por otro

(A) Figura 5. Mapa de crecimiento de Soacha en relación con la industria durante la década de 1970

Fuente: elaboración propia, tomando como referencia la base geográfica del Instituto Geográfico Agustín Codazzi (IGAC), (2016) CC BY-NC lado, si la vivienda está en alquiler, se profundiza al indagar sobre el lugar en el que le gustaría vivir y la razones para tomar la decisión de vivir en el municipio. También se establecen preguntas que buscan identificar en qué comuna se encuentra y cuánto tiempo lleva viviendo en el municipio. En la tercera se preguntó sobre el grado de conocimiento frente a las características arqueológicas, ambientales, culturales y turísticas del municipio.
En la cuarta se identificaron los medios por los cuales las personas conocen aspectos del municipio y, finalmente, en la quinta parte se indaga por la percepción que tienen sobre los cambios en el crecimiento urbano del municipio.

El ejercicio de las encuestas contó con un grupo focal de contraste, el cual participó de una formación en agricultura urbana y apropiación del municipio a través de la Escuela de Agricultura Urbana $^{5}$, ya que, justamente, la encuesta se aplicó al finalizar los módulos de formación. Es importante tomar en cuenta que dentro del aspecto metodológico era necesario identificar actores dentro del municipio que estuvieran propiciando estrategias de apropiación del territorio, para revisarlas y analizarlas a la luz de los objetivos de la investigación.

El trabajo de cartografía social se realizó con dos grupos poblacionales: el primero, con padres de familia de una institución educativa de preescolar, en el contexto de la celebración de la semana cultural. Con esta población se desarrolló como tema el conocimiento sobre el municipio de Soacha. El segundo grupo, con algunas familias que tuviesen una trayectoria de más de 30 años en el municipio. La actividad se realiza en diferentes momentos, y en cada grupo se organizaron mesas de trabajo con cuatro y cinco personas a cada una, y a quienes se les entregó el mapa del municipio: en él debían señalar los sitios de recordación o significativos, junto con la fecha (categoría identidad) y si dicho lugar aún existía o había sido trasformado dentro del marco del crecimiento urbano del municipio (categoría territorio).

En la figura 4 se presentan tanto el esquema de síntesis conceptual como el esquema de análisis con los aspectos y las categorías que propone la investigación.

\section{Resultados}

\section{Soacha a la luz de los Planes Nacionales de Desarrollo (PND)}

Durante el gobierno de Misael Pastrana (19701974), en su PND, Ilamado Las cuatro estrategias, se invita a planear de forma inmediata el proceso de urbanización acelerando la industrialización. Se orienta el desarrollo para que las ciudades aumenten la capacidad de asimilación de emigrantes. Junto con el planteamiento de propuestas de desarrollo urbano regional, se da impulso a la actividad industrial en centros urbanos intermedios, lo cual lleva a un crecimiento menos acelerado (Departamento Nacional de Planeación [DNP], 1972).

\footnotetext{
5 La Escuela de Agricultura Urbana es un proyecto de dos corporaciones del municipio de Soacha, Jardines de Sion y Caminando el Territorio. Estas capacitaron, aproximadamente, a 50 personas de diferentes edades frente a temas de agricultura urbana y realizaron tres caminatas de reconocimiento del territorio. También lograron una vinculación con el Colegio María Auxiliadora y la capacitación de 40 estudiantes.
} 
Es, justamente, la actividad industrial que se desarrolla en el municipio de Soacha la que hace que el fenómeno de migraciones campesinas sea fuerte durante los años setenta del siglo XX. El desarrollo urbano se comienza a gestar con fuerza a partir de los asentamientos de los llamados picapedreros, en la Comuna 6, en los barrios que hoy se conocen como Cagua, San Marcos y San Humberto. Además, Soacha presenta una oferta de industria textil e industrial, con ejemplos como Stanton S. A., creada en 1974; Espumados S. A., en 1975, y Textiles KonKor S. A., en 1977, entre otros. Se puede observar en la figura 5 cómo la localización de dicha industria genera dos focos en los extremos de la parte urbana del municipio y un hito importante es la construcción de la urbanización Compartir, hacia 1974.

\section{Soacha, industrial y superpoblada}

La década de 1980 se caracteriza por el flujo de población campesina a las ciudades ${ }^{6}$, por lo que la apuesta en los PND durante los mandatos de Belisario Betancur Cuartas (1982-1986) y de Virgilio Barco Vargas (1986-1990) se orientan fuertemente al ordenamiento territorial de las diversas regiones del país tomando como base las cuencas hidrográficas (DNP, 1983).

Según el plan de desarrollo (DNP, 1987) presentado durante el gobierno de Virgilio Barco (19861990) se buscó privilegiar la gestión municipal, y los principales frentes de acción se orientaron a:

1. Desarrollar el crecimiento urbano ordenado

2. Garantizar una adecuada provisión de la infraestructura urbana

3. Promover la investigación y la transferencia tecnológica

4. Consolidar los instrumentos de planeación

Soacha es un municipio donde el crecimiento poblacional aumenta considerablemente (figura 6); así mismo, vive el primer momento de auge de las urbanizaciones de vivienda unifamiliar y bifamiliar, junto con edificaciones de multifamiliares, financiadas, principalmente, por las corporaciones de ahorro y vivienda (CAV) y el Fondo Nacional del Ahorro (FNA); el sistema colombiano de ahorro y vivienda se consolida como uno de los principales intermediarios financieros de la economía nacional.

Para 1986, el PND (DNP, 1987) consolida programas y proyectos sectoriales, así como el desarrollo de planes regionales y municipales; las oficinas de planeación de los institutos de orden nacional o las de carácter municipal orientan la re-densificación y la consolidación de las ciudades, con el apoyo de entidades estatales como el Instituto de Crédito Territorial (Inscredial), el Banco Central Hipotecario $(\mathrm{BCH})$ y el FNA.

6 Situación que se plantea tanto en el capítulo de política social del plan de desarrollo del presidente Betancur Cuartas (DNP, 1983) como en el diagnóstico del plan de desarrollo del presidente Barco Vargas (DNP, 1987).
Como se muestra en la figura 7, en 1989 el proceso de urbanización se va consolidando y se van identificando dinámicas claras de sectores de vivienda alrededor de los sectores industriales y hacia la periferia del casco urbano del municipio, en Altos de Cazucá, donde se construye Ciudadela Sucre; es decir, tanto en los límites con Bogotá hacia el oriente, y en especial hacia ciudad Bolívar, como con el borde del río Bogotá, al occidente del municipio.

\begin{tabular}{|c|c|c|c|c|c|}
\hline \multicolumn{6}{|l|}{100000} \\
\hline \multicolumn{6}{|l|}{80000} \\
\hline \multicolumn{6}{|l|}{60000} \\
\hline \multicolumn{6}{|l|}{40000} \\
\hline \multicolumn{6}{|l|}{20000} \\
\hline 0 & -1 & 2 & 3 & 4 & 5 \\
\hline - CENSO AÑO & 1938 & 1951 & 1964 & 1973 & 1985 \\
\hline P. TOTAL & 15.159 & 20.441 & 32.600 & 39.405 & 105.413 \\
\hline P. URBANA & 2.006 & 4.226 & 11.435 & 23.997 & 99.953 \\
\hline P. RURAL & 13.153 & 16.215 & 21.165 & 12.408 & 5.451 \\
\hline
\end{tabular}

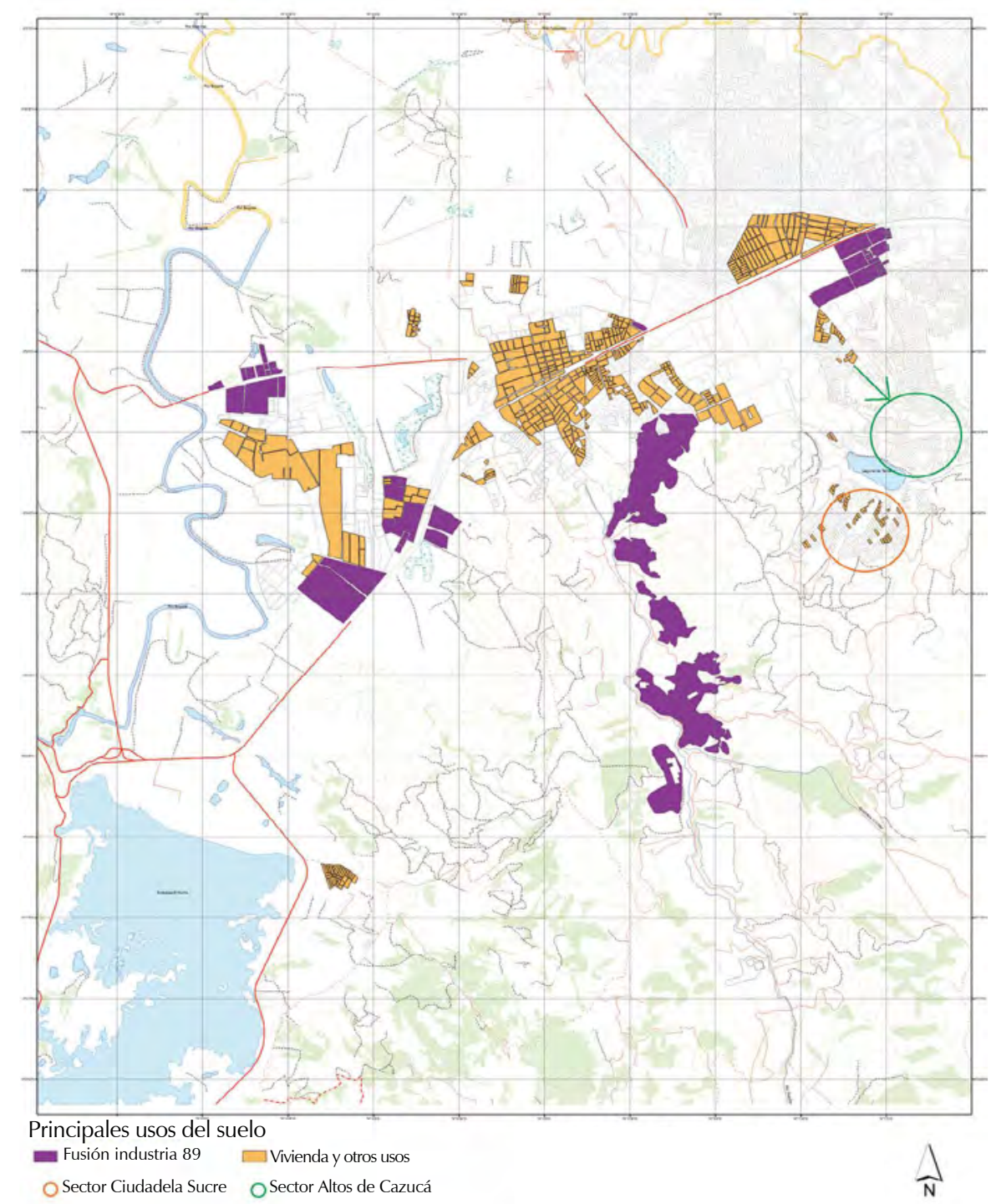

A Figura 7. Mapa de localización de industria y vivienda en Soacha para 1989 Fuente: elaboración propia. Referencia tomada de la base geográfica del IGAC (2016) CC BY-NC.
(7) Figura 6. Tendencia de crecimiento poblacional entre 1938 y 1985 en el municipio de Soacha

Fuente: elaboración propia. Datos tomados del Departamento Administrativo Nacional de Estadística (DANE) (2015). 
(1) Figura 8. Tendencia de crecimiento población en Soacha entre 1970 y la década de 1990

Fuente: elaboración propia. Datos tomados del Departamento Administrativo Nacional de Estadística (DANE).
Soacha: la esperanza de un lugar económico y propio

Durante el inicio del gobierno de César Gaviria (1990-1994), en su plan de desarrollo (DNP, 1991) se orienta a los municipios para que asuman la responsabilidad de sus propios procesos de urbanización en relación con: saneamiento básico; construcción, mantenimiento y dotación de la infraestructura del primer nivel de atención médica, y construcción, dotación y mantenimiento de planteles escolares e instalaciones deportivas.

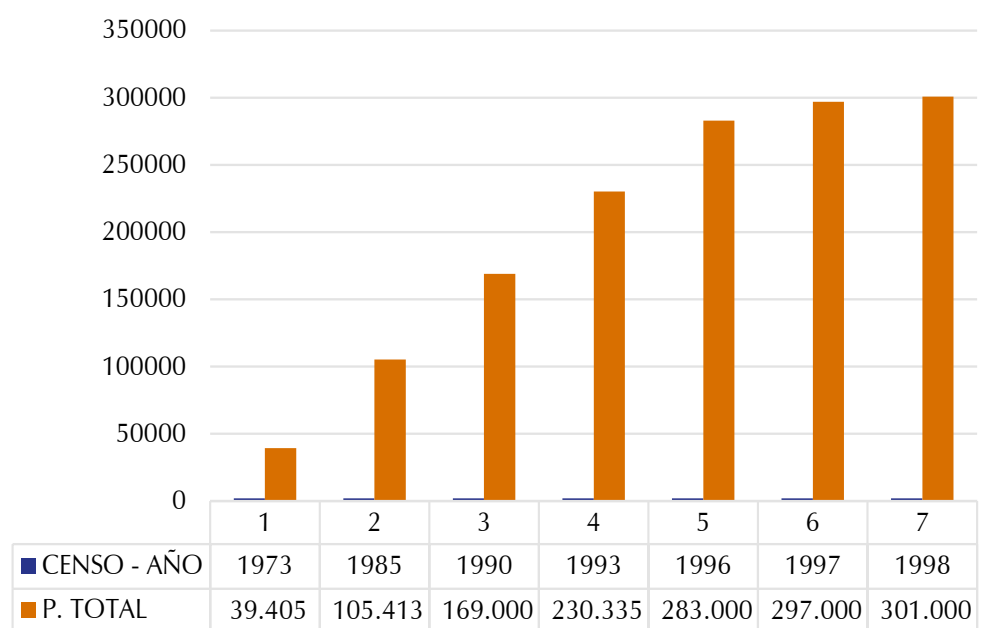

Posteriormente, en el plan de desarrollo (DNP, 1995) durante el gobierno de Ernesto Samper Pizano (1994-1998) se propone el Programa de Vivienda Nueva, el cual, en su propuesta, incluye viviendas mínimas o unidades básicas; además, se plantea la política de adecuación de tierras con la participación activa de los usuarios desde la identificación del proyecto hasta la administración de este.

Para el caso del municipio de Soacha, uno de los procesos de ocupación del territorio se genera a partir de los pactos de paz con el movimiento guerrillero Movimiento 19 de Abril (M-19) (Pérez, 2004). A raíz del proceso de reinserción, en 6 años (entre 1993 y 1999) la población del municipio aumenta en el 51,52\%, aproximadamente, como se puede observar en la figura 8.

De igual manera, durante la misma época el tema de la prevención y la atención de desastres se asume con mayor fuerza: se elaboran mapas de riesgos y se impulsa la aplicación de medidas de control, protección y ordenamiento físico, al promover la incorporación de estos componentes en los planes de desarrollo territorial y de ordenamiento urbano, de acuerdo con lo estipulado en la Ley 9 de 1989.

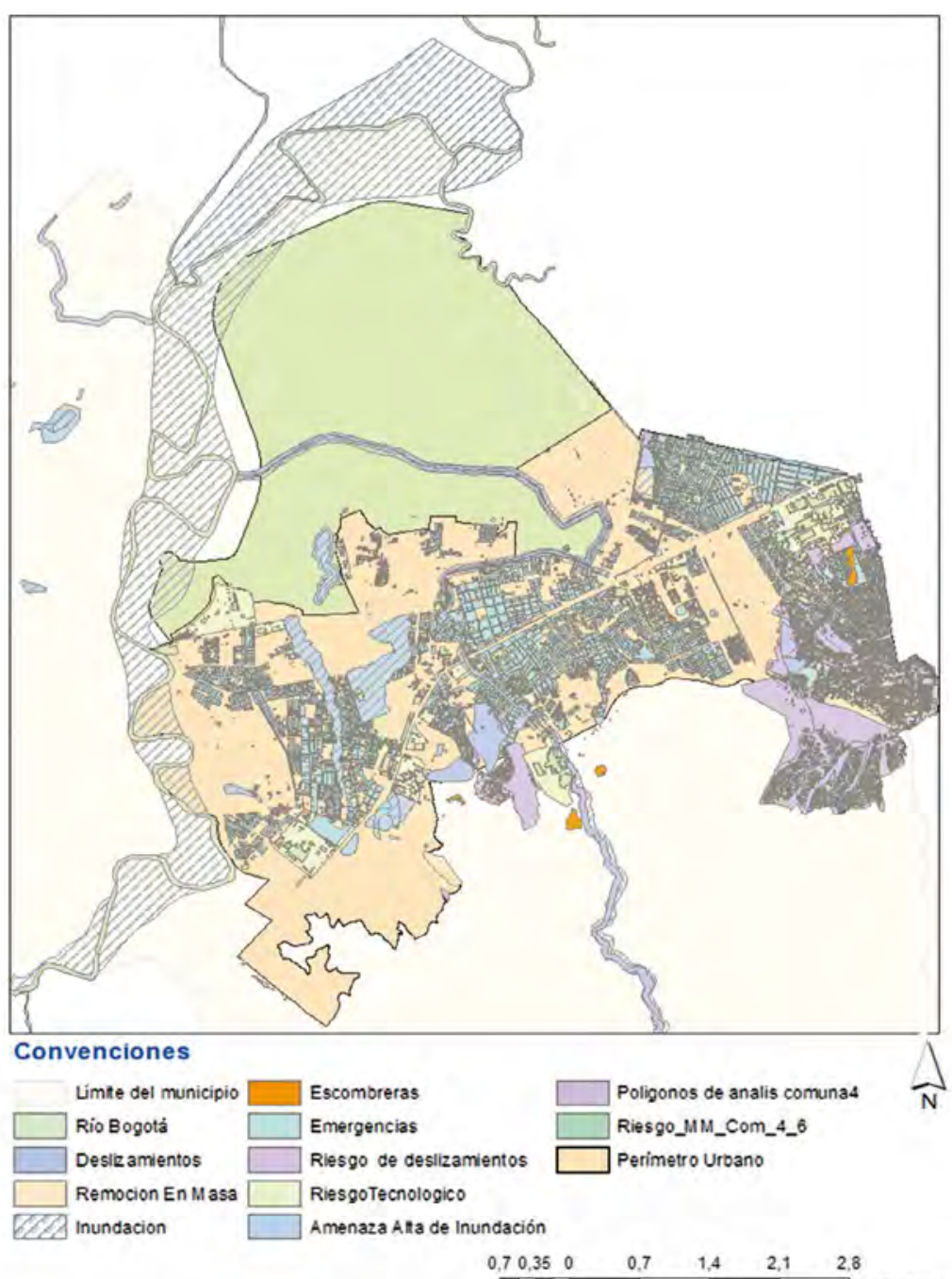

(A) Figura 9. Zonas de riesgo del municipio de Soacha (1990) Fuente: elaboración propia, con datos de la base geográfica del IGAC. CC BY-NC.

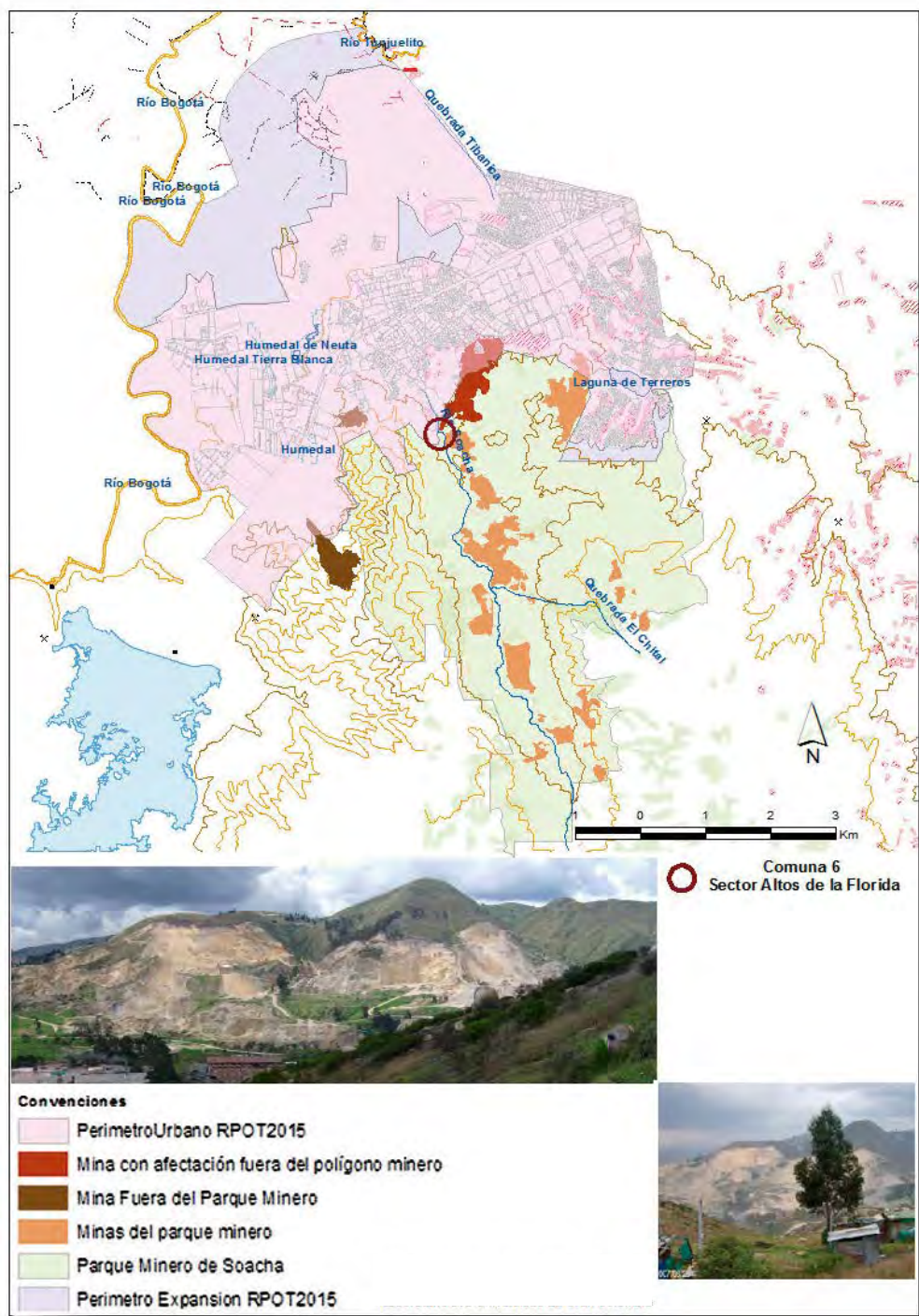

A Figura 10. Localización de los principales sitios de explotación minera a cielo abierto en la comuna 6 (Altos de la Florida)

Fuente: elaboración propia, con datos de la base geográfica del IGAC (2016). CC BY-NC. 
En la figura 9 se muestra, en el plano del municipio, la localización de las zonas de riesgo dentro del casco urbano. Es importante anotar que un gran número de barrios de origen informal, justamente, se asientan en estos sectores de las comunas 4 y 6 del municipio, con lo cual la imagen del desplazamiento forzado y la informalidad se empiezan a relacionar con las zonas de riesgo.

Por su parte, el Ministerio de Medio Ambiente realiza los estudios necesarios para identificar áreas compatibles con la actividad minera en la Sabana de Bogotá, a fin de formular el Plan de Ordenamiento Minero ${ }^{7}$. Frente a este aspecto, es importante tomar en cuenta que en Soacha, durante la década de 1990, aumenta de forma considerable la explotación minera a cielo abierto, y su impacto ambiental es evidente ${ }^{8}$, como se puede apreciar en la figura 10 para las comunas 4,5 y 6 , aunque la situación también es crítica en las comunas 4 y 5 , aspectos que comienzan a fortalecer un imaginario del municipio, relacionado, justamente, con el deterioro del paisaje natural.

\section{Soacha: tierra de migrantes por el conflicto armado}

El diagnóstico que se presenta en el PND del gobierno de Andrés Pastrana (1998-2002) señala la debilidad del modelo de ordenamiento territorial vigente por entonces en Colombia, lo cual se refleja en la baja gobernabilidad (ilegitimidad y ausencia del Estado en algunos puntos de la geografía nacional; violencia regional y local), entre otros aspectos:

[...] uso inadecuado de los recursos; deterioro ambiental; marginalidad de los territorios y sectores sociales; confusión y duplicidad de funciones entre entidades y clases del Estado; falta de reconocimiento de la diversidad cultural, étnica de las regiones, así como de los territorios indígenas. (Departamento Nacional de Planeación, 1998, p. 169)

Entre 2001 y 2005 Ilegan a Bogotá y a Soacha 235.126 personas provenientes de 29 de los 33 departamentos del país. Para el periodo 2006-2008 se incrementa el número de personas en situación de desplazamiento. Se producen 66 desplazamientos masivos, cuyas víctimas se ubican, en su gran mayoría, en la localidad de Ciudad Bolívar (Bogotá) y en Cazucá (Soacha). El censo de 2005 revela un incremento poblacional de 402.007 habitantes, de los cuales hay 396.555 en la zona urbana, y 5.452, en la zona rural; un dato que para un buen número de pobladores es mayor que el revelado por el Departamento Administrativo Nacional de Estadística $^{9}$ (DANE, 2010).

\footnotetext{
7 Este plan fue propuesto en el plan de desarrollo del presidente Ernesto Samper (DNP, 1994), en el capítulo 7, sobre e medio ambiente y las extracciones limpias.

8 Para 2007 se tiene un registro de 52 explotaciones mineras a cielo abierto, según el estudio para el ordenamiento de la minería de materiales de construcción y arcillas (Cámara de Comercio de Bogotá, 2005).

9 Posteriormente se contrastarán las cifras que presenta el
}

Los planes de gobierno de este inicio de siglo plantean estrategias orientadas a fortalecer los procesos de planificación y gestión estratégica con una mirada de ciudad-región. En relación con la dinámica de asentamientos humanos y entorno urbano, el Gobierno nacional apoya a las entidades territoriales que organicen programas de regularización y rehabilitación integral de barrios, se vinculen a programas de prevención y mitigación de riesgos, logren la recuperación del espacio público y contemplen la dotación de equipamiento público comunitario. ${ }^{10}$ (DNP, 2014).

No obstante lo anterior, en Soacha se acogen macroproyectos de interés social nacional antes de atender el mejoramiento de los barrios y la mitigación de riesgo en algunos sectores. Entre dichos macroproyectos se reconoce Ciudad Verde (Resolución 1687 de 200911), adjudicada a varias constructoras, además de Hogares Soacha y Maiporé, entre otros, que ponen en riesgo la estructura ecológica del municipio (incluyendo los humedales), así como la seguridad alimentaria, al ampliar la zona de expansión urbana a esos sectores (figura 11).

DANE con los estudios realizados por el CODHES, ACNUR y CINEP.

10 El Gobierno nacional otorgará incentivos tributarios para promover programas y proyectos de renovación urbana en las principales ciudades del país. En este sentido, se apoyará la participación privada en la financiación de proyectos y se darán incentivos para la vinculación de inmuebles en zonas que, si bien presentan un alto grado de deterioro social y físico, cuentan con potencial para la renovación.

11 Modificada por las resoluciones 1434 del 27 de julio de 2010, 1355 del 6 de julio de 2011 y 0182 del 20 de marzo de 2015.

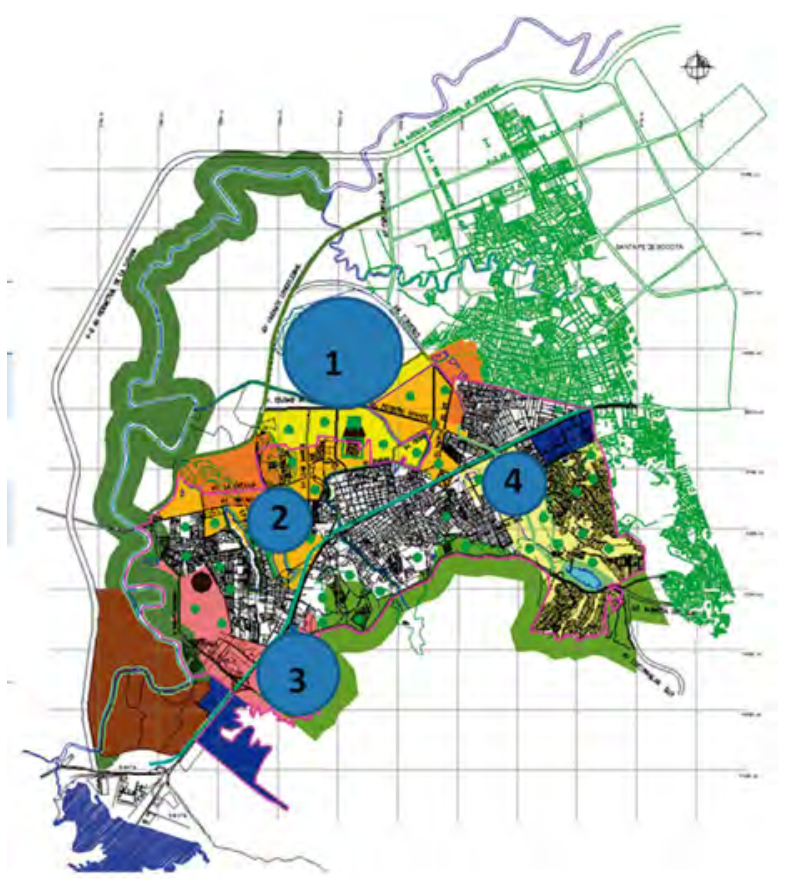

\begin{tabular}{l}
\hline Megaproyecto \\
\hline 1. Ciudad Verde (Constructoras) \\
2. Parque Campestrem (C. Bolívar) \\
3. Ciudadela Colsubsidio Maiporé \\
$\begin{array}{l}\text { 4. Proyectos de vivienda de menor } \\
\text { escala (C. Bolívar) }\end{array}$ \\
\hline
\end{tabular}

\& Figura 11. Localización de los megaproyectos y otras soluciones de vivienda en Soacha Fuente: elaboración propia, sobre plano de Corredores de Vida Ambiental POT 20082011 (2017). CC BY-NC. 


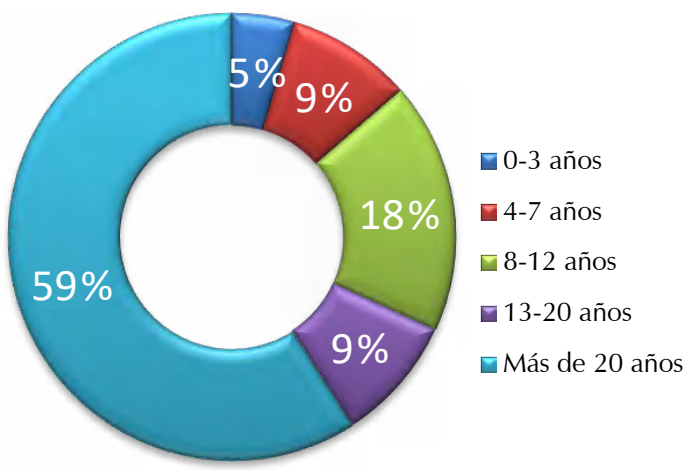

(A) Figura 12. Tiempo de permanencia en el municipio de Soacha

Fuente: elaboración propia (2017).

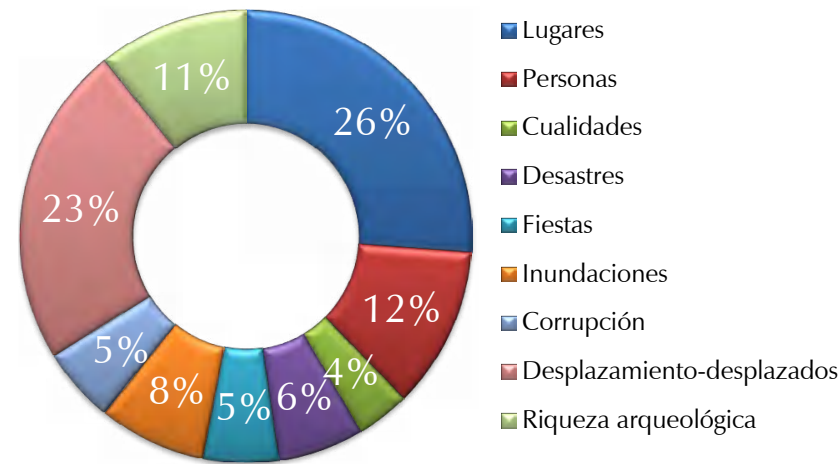

(A) Figura 14. Imaginarios sobre el municipio de Soacha por parte de quienes viven en Bogotá

Fuente: elaboración propia (2017).

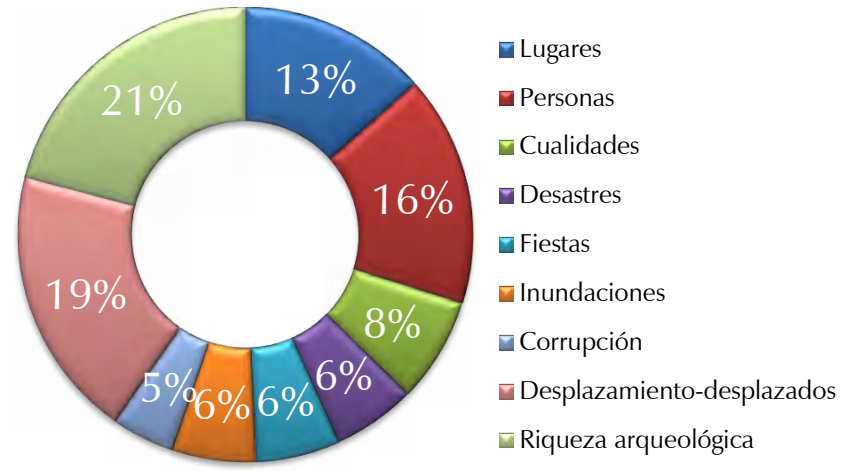

(A) Figura 16. Imaginarios sobre el municipio de Soacha por parte del grupo focal

Fuente: elaboración propia (2017).

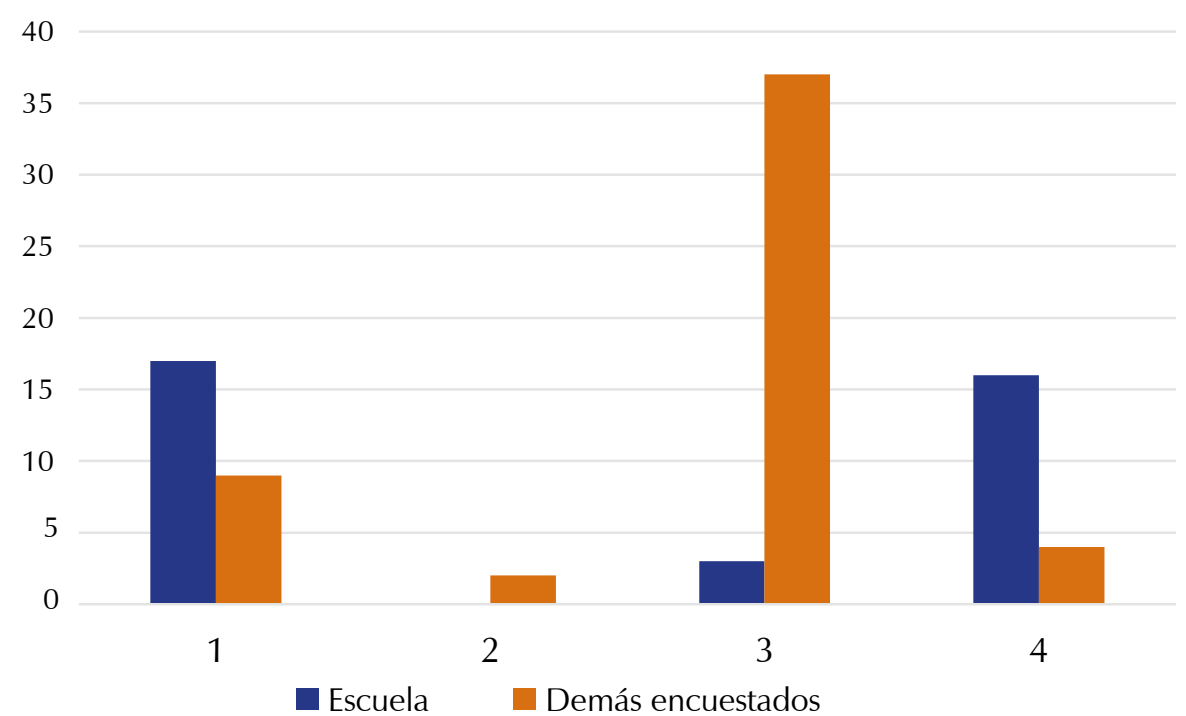

(A) Figura 17. Respuestas a la pregunta: "¿Soacha tiene sitios de valor arqueológico?" Fuente: elaboración propia (2017).

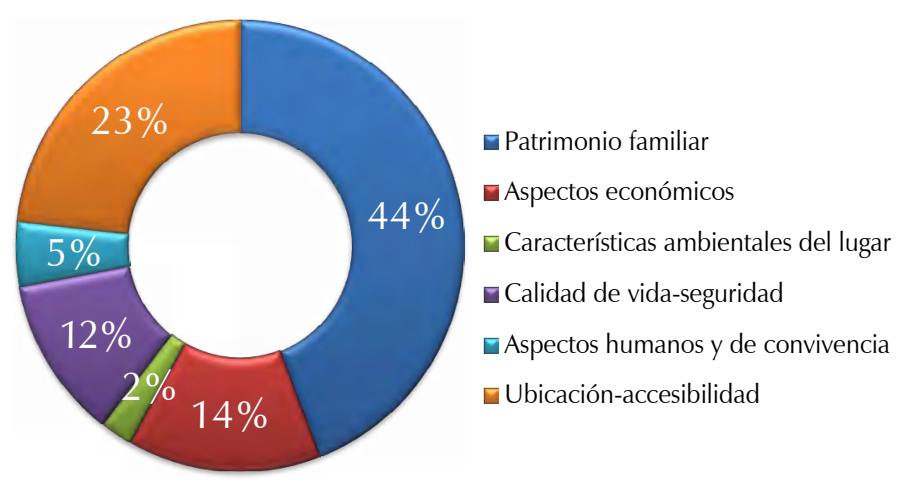

(1) Figura 13. Resultados generales de todos los encuestados en relación con el imaginario en general

Fuente: elaboración propia (2017).

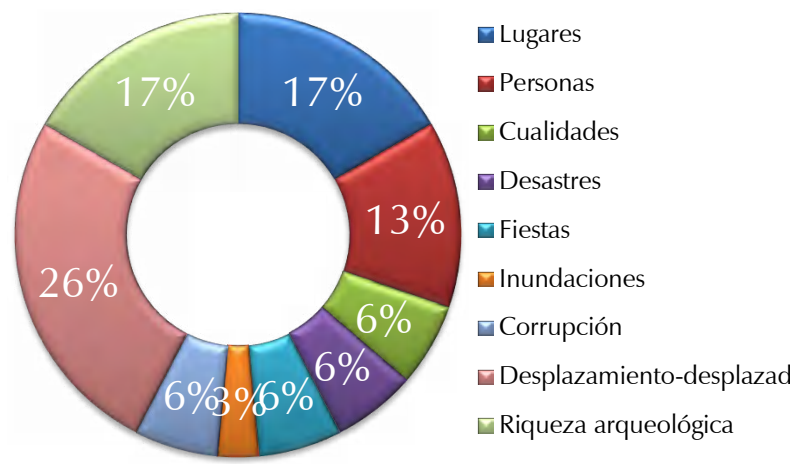

(4) Figura 15. Imaginarios sobre el municipio de Soacha por parte de quienes viven en este municipio

Fuente: elaboración propia (2017).

\section{Soacha a la luz de los encuestados}

En relación con las encuestas ${ }^{12}$, se encontró que si bien hay un grupo significativo de personas que llevan más de 20 años viviendo en el municipio (figura 12), muchos de ellos manifestaron conocerlo muy poco, y señalaron que el espacio de formación sobre Soacha les permitió conocer más de su municipio y valorar su riqueza.

Para analizar los resultados en relación con los imaginarios sobre el municipio, se elaboraron cuatro tipos de gráficas (figuras 13 a 15): una con los datos totales, otra con las respuestas de quienes viven en Soacha, la siguiente con las respuestas de quienes viven en Bogotá y una final con las respuestas del grupo focal.

Los dos aspectos más fuertes se relacionan con una remembranza o una imagen de lugares significativos y de personas como los desplazados; es decir, el imaginario del municipio como lugar de desplazados (figura 13).

Por su parte, quienes viven en Bogotá perciben al municipio como carente de cualidades, no lo reconocen por sus características históricas o ambientales (figura 14).

No obstante lo anterior, para quienes viven en Soacha las características arqueológicas y lugares como el Parque Principal, la Iglesia de Soacha, las canchas de fútbol de Norte (único sector amplio que tenían los habitantes del municipio

12 Solo se relacionan los resultados pertinentes a la temática del artículo. 


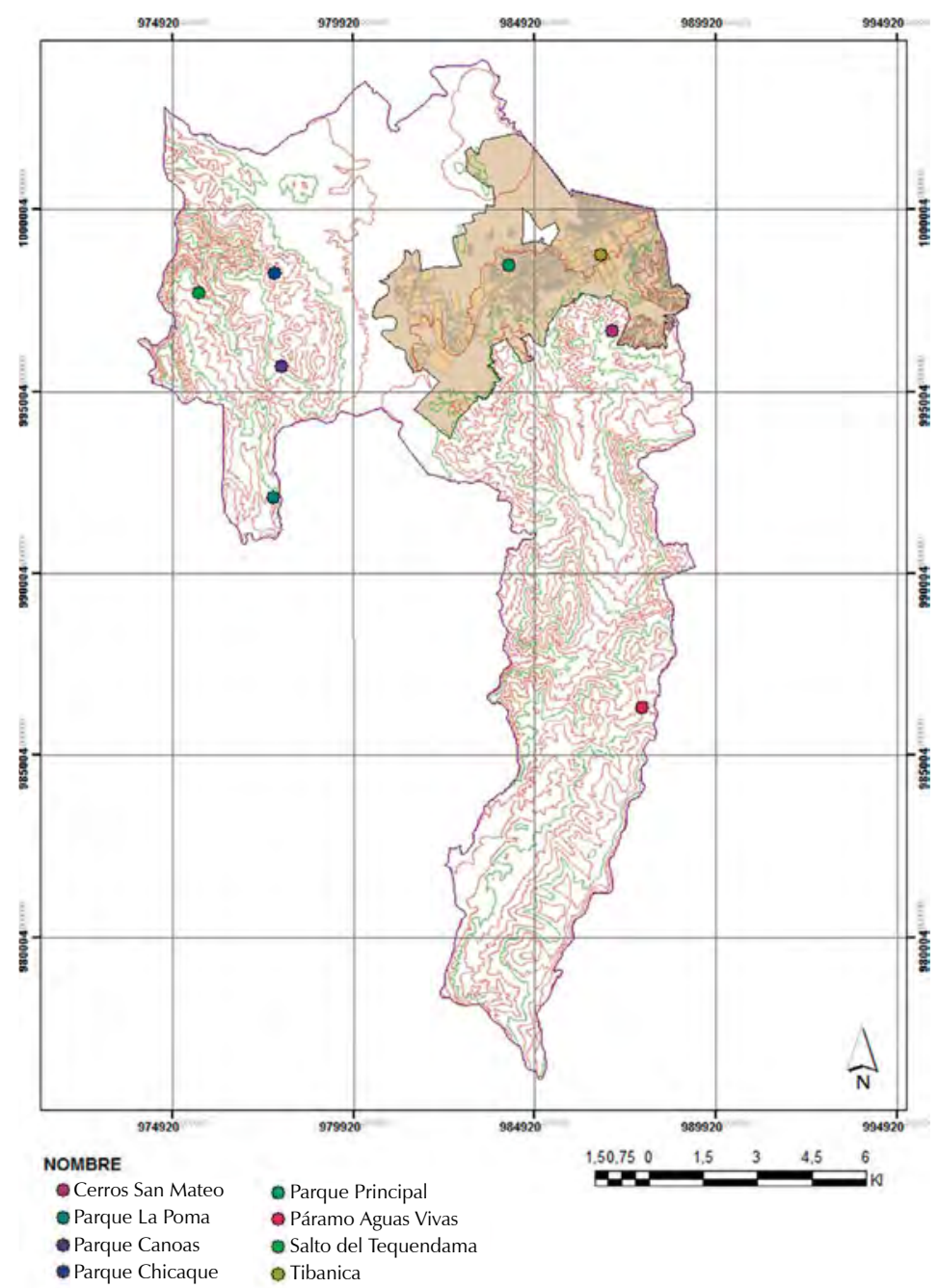

(A) Figura 18. Plano de localización de los lugares con valor arqueológico reconocido por los encuestados

Fuente: elaboración propia (2017) CC BY-NC.

para el deporte, y que actualmente está en gran parte urbanizado) y algunos teatros que ya no existen sí son significativos ${ }^{13}$, como se puede observar en la figura 15.

Por otra parte, también contrastan los resultados del grupo focal, quienes ponderan con el valor más alto la riqueza arqueológica del municipio (figura 16), sin desconocer la realidad del desplazamiento forzado, al configurarse Soacha como uno de los lugares de mayor recepción de esta clase de población.

A continuación, se presentan resultados comparativos entre el grupo focal y los demás encuestados en relación con el conocimiento del territorio sobre los aspectos arqueológico, cultural, ambiental y turístico, junto con la georreferenciación (figura 17) de los lugares según el aspecto que se esté tratando.

En relación con el aspecto arqueológico, es claro que quienes participaron en el grupo focal (figura 18) manifiestan tener un alto conocimiento de los sitios de valor arqueológico del municipio y una clara recordación de dichos sitios, como aparece en la figura 18.

13 Esto se detectó en el trabajo realizado con cartografía social, en el cual cada grupo señalaba los lugares más significativos sin tener presente su transformación actual.

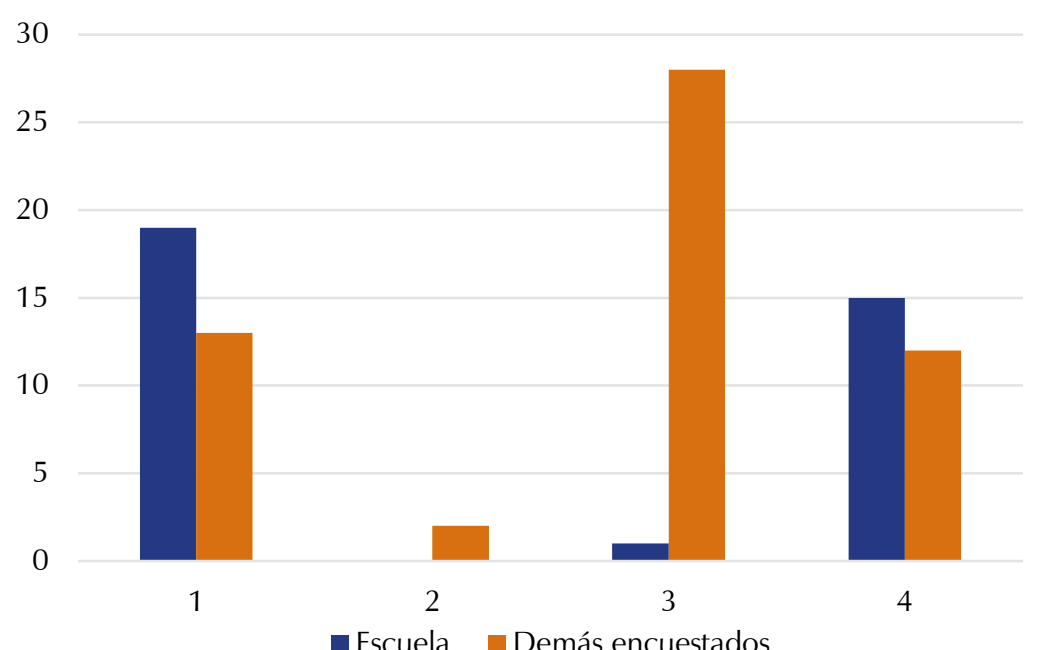

(A) Figura 19. Respuestas a la pregunta: “¿En Soacha se realizan actividades culturales?"

Fuente: elaboración propia (2017).
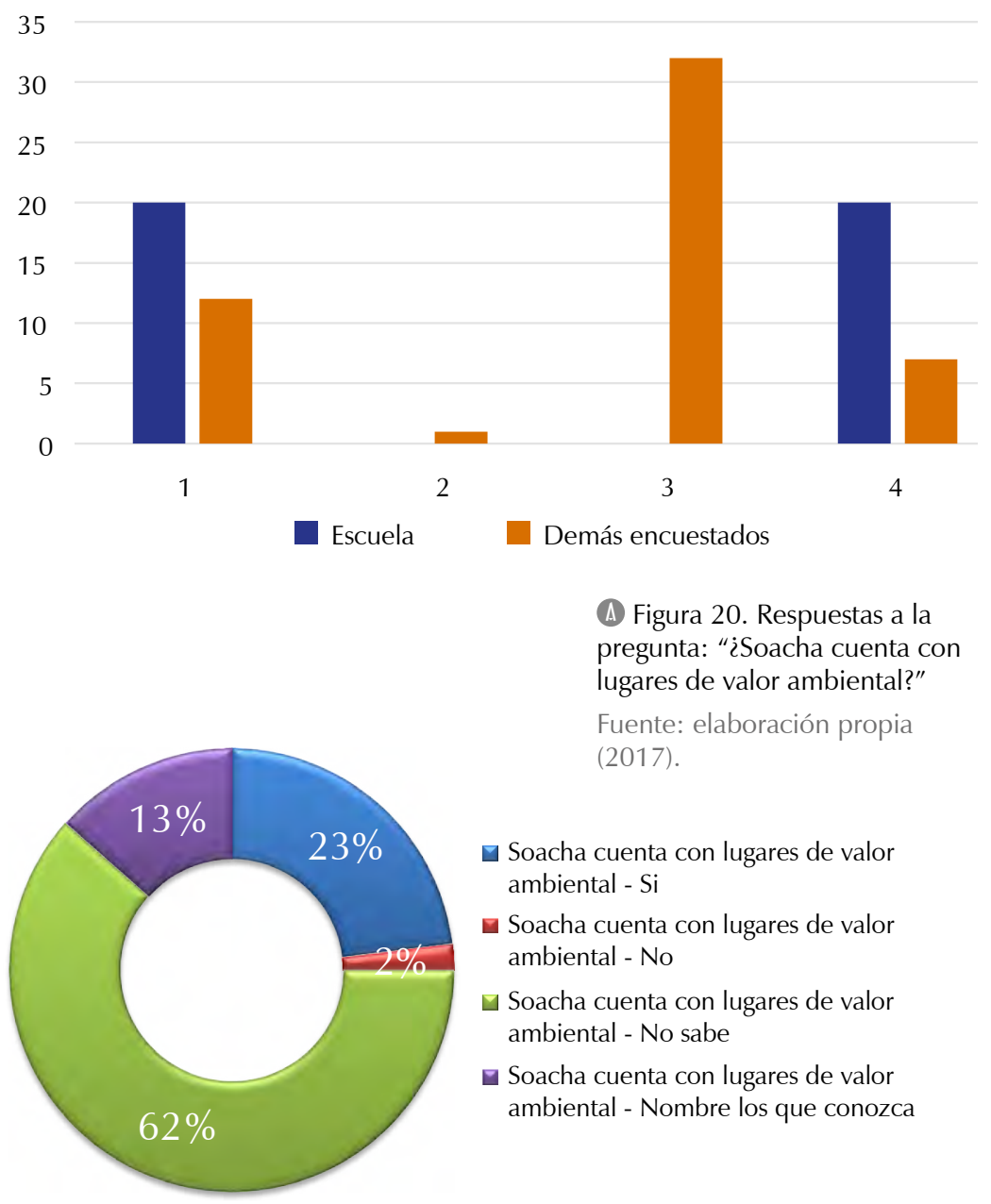

(A) Figura 20. Respuestas a la pregunta: "¿Soacha cuenta con lugares de valor ambiental?" Fuente: elaboración propia (2017).

- Soacha cuenta con lugares de valor ambiental - Si

- Soacha cuenta con lugares de valor ambiental - No

$\square$ Soacha cuenta con lugares de valor ambiental - No sabe

- Soacha cuenta con lugares de valor ambiental - Nombre los que conozca

Sobre las actividades culturales que se realizan en el municipio, el contraste es fuerte entre quienes participan en el grupo focal (figura 19) y quienes no: los primeros tienen claridad sobre las actividades culturales del municipio y las pueden identificar, pero para el segundo grupo de personas el desconocimiento es del $51 \%$ en relación con este aspecto.

Frente a los lugares de valor ambiental, el 100\% de los participantes del grupo focal reconocen los principales lugares de valor ambiental del municipio (figura 20) frente al $62 \%$ que manifiestan que no saben o no reconocen los lugares de valor ambiental que existen en el municipio (figura 21).
(A) Figura 21. Reconocimiento de los lugares de valor ambiental por parte de los que no participaron en el proceso de formación

Fuente: elaboración propia (2017). 


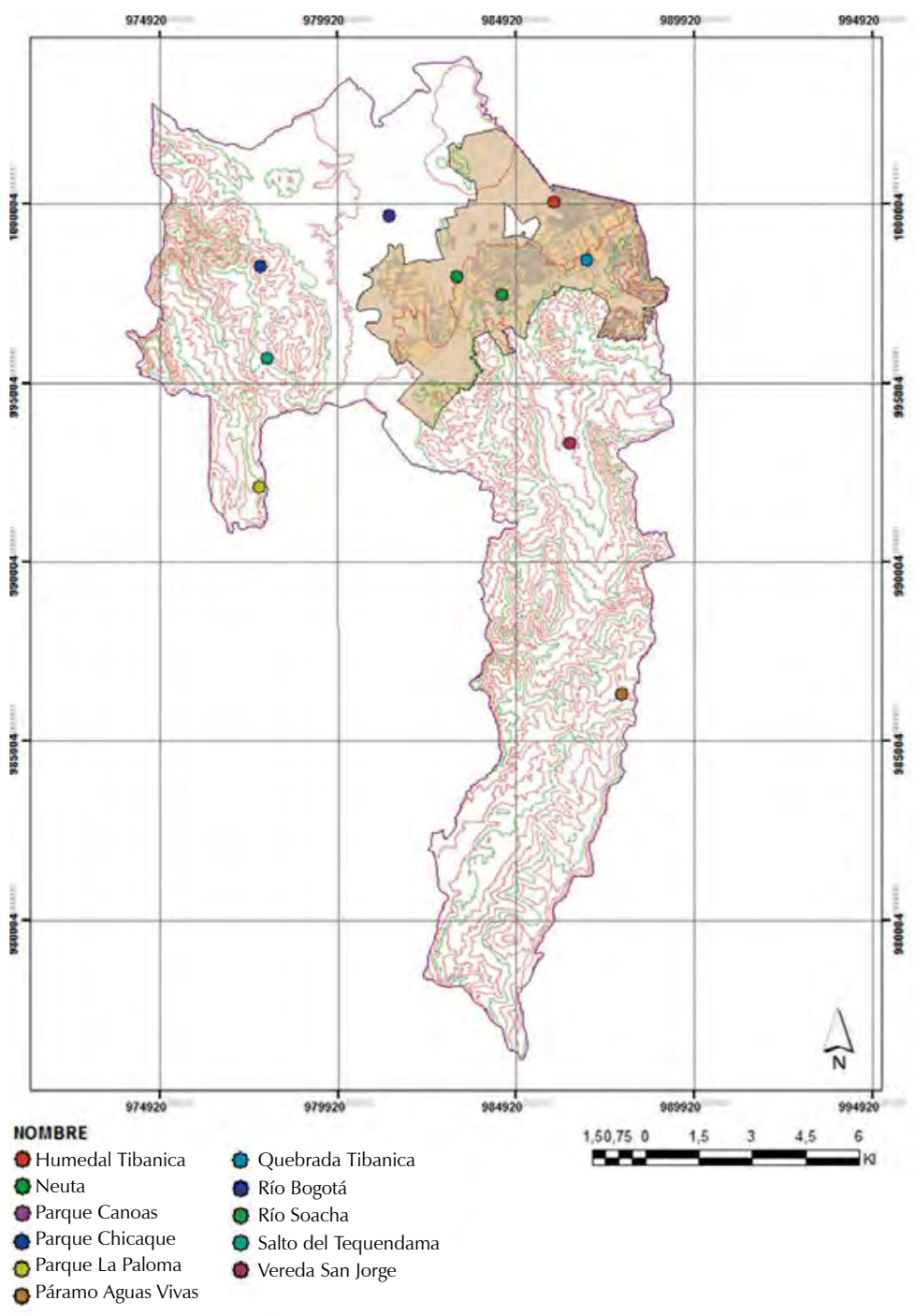

(A) Figura 22. Lugares de reconocimiento de valor ambiental

Fuente: elaboración propia (2017) CC BY-NC.

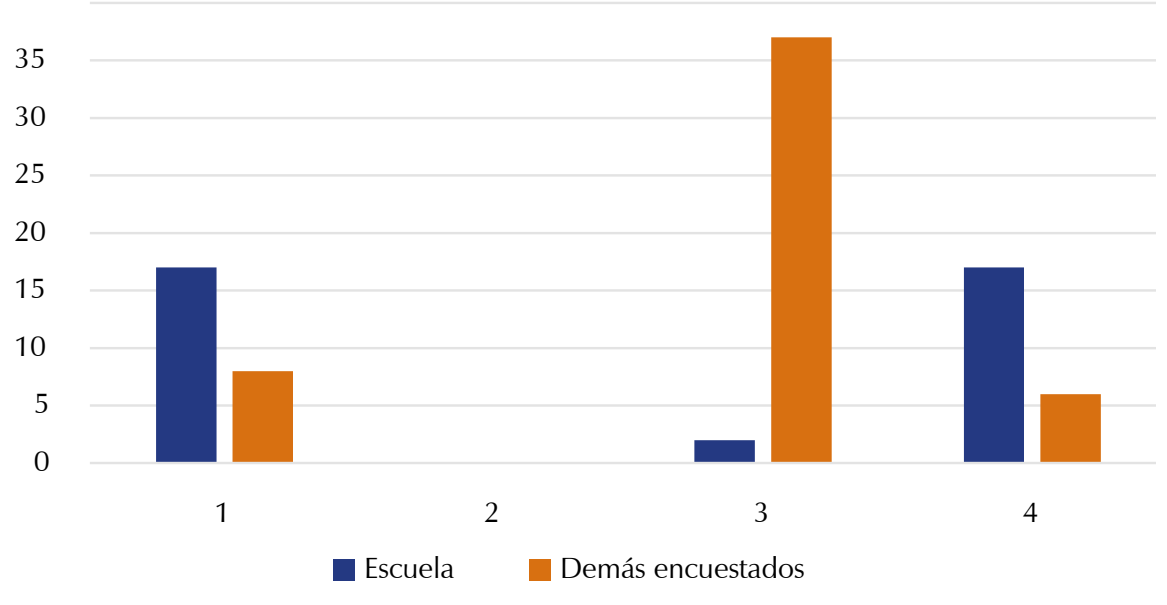

(A) Figura 23. Respuestas a la pregunta: "¿Soacha cuenta con lugares de valor turístico?"

Fuente: elaboración propia (2017).
En la figura 22 se relacionan los lugares de valor ambiental que señalan los encuestados; vale la pena señalar que los que tienen un mayor reconocimiento son el Parque Cagua, el Parque Chicaque, el páramo de Aguas Vivas y Canoas; también, que algunos de dichos lugares hicieron parte de los recorridos.

Finalmente, tanto para quienes participaron en el grupo focal como para los demás encuestados, es claro que el municipio cuenta con lugares de valor turístico; quienes participaron en la formación tienen un mayor conocimiento de estos lugares y los relacionan, justamente, con los que tienen valor ambiental, arqueológico e histórico, tales como las haciendas. A continuación se presentan la gráfica comparativa y el plano que da cuenta de dichos resultados (figuras 23 y 24).

Dentro de la encuesta se preguntó a los participantes qué identifica, para ellos, el municipio o hacia dónde debe proyectarse su futuro. Las respuestas están dentro de las siguientes categorías: [valor] social, valor de la riqueza por descubrir, valor de los aspectos ambientales, culturales e históricos y del compromiso. Entre las respuestas se destacan también algunos eslóganes:

"La ciudad de las oportunidades, la ciudad del varón del sol".

"Soacha no es lo que escuchas, sino lo que sientes y vives".

"Ven a conocer Suacha, y te enamorarás de ella".

"Suacha, un territorio para descubrir sus maravillas".

"Portal de la prosperidad de los muiscas".

"Trabajemos por recuperar nuestro municipio".

"Soacha, paraíso sagrado de los muiscas".

"Suacha es cultura, diversidad y vida".

Como resultado se pudo observar que el mayor número de eslóganes giran en torno al compromiso que hay que tener por el municipio, y en una segunda instancia, en torno a la necesidad de recuperar la riqueza ambiental, cultural e histórica del municipio.

\section{Discusión}

La caracterización de los imaginarios, individuales o colectivos, invita a considerar claramente la noción de territorialidad, pues el desarrollo de dicha caracterización parte de la formación de territorios, sin tener en cuenta las consecuencias que se producen en la interacción de las comunidades con su contexto inmediato. El retorno del territorio, según Milton Santos (1997), es simultáneo a la agrupación de diversos análisis que concuerdan en jerarquizar la dimensión espacial al mismo tiempo que señalan su pérdida de capacidad para operar como referente de las identidades sociales;

\footnotetext{
[...] los territorios habitados (por personas comunes) se confrontan con dos fenómenos contemporáneos; la expansión y la imposición de las relaciones capitalistas de producción, las formas de interacción que llevan a los proceso de mundialización o globalización y, por otro, la tendencia de homogenización de las costumbres las tradiciones y los usos que se da a la ciudad sobre todo con respecto al consumo y la perspectiva individual. (Schneider \& Peyre, 2006, p. 78)
} 
El imaginario colectivo es la interacción dinámica que se va construyendo a través de las imágenes que se generan de un lugar, las cuales afectan el comportamiento y la relación de las personas o la comunidad sobre él. Al ser dinámi$\mathrm{CO}$, se configura en una relación temporal, tanto lineal como cíclica, como se muestra en la figura 25 , y que puede tener sus bases en las relaciones de la comunidad con un pasado; es decir, la realidad de los primeros asentamientos junto con los procesos de consolidación y transformación del territorio, los cuales influyen o determinan su presente, un presente con huellas del pasado, con nuevos actores y realidades que, al identificar estas dinámicas, permitirá construir nuevos imaginarios por las nuevas relaciones que se puedan establecer entre las personas y los lugares, en función de una nueva realidad social.

Además de lo anterior, el imaginario está cargado del poder de validar una realidad o de estigmatizar un territorio o un grupo poblacional, un aspecto que invita a reflexionar sobre prácticas individuales y colectivas en el espacio urbano a manera de señas y marcas de la vida urbana, ejes de sentido y ciudades imaginadas desde sus habitantes y desde sus dirigentes. Soacha tiene el estigma de ser un municipio con una dinámica de ciudad dormitorio, de ingobernabilidad, de corrupción, de destrucción de sus propios recursos y de desconocimiento de su valor arqueológico, de lugar de los desplazados y los migrantes.

Realizar este recorrido de crecimiento y transformación urbana del municipio desde la incidencia de los planes nacionales de desarrollo, y, a su vez, desde los aspectos conceptuales, no fue una tarea fácil, pero sí bastante enriquecedora, una tarea que permitió detectar la permeabilidad de la administración municipal frente a las propuestas de orden nacional; en especial, frente a los temas de vivienda y movilidad.
Tal parece que se da prioridad a las demandas habitacionales, principalmente de Bogotá, antes que responderse a las necesidades ambientales, sociales, económicas y culturales del municipio, y en dicho proceso ocurren dos cosas de interés para la investigación: primero, se da una apertura mayor a las nuevas urbanizaciones, sin solicitar o sin generar en estos proyectos elementos que se relacionen con la identidad del municipio. A eso se suma la publicidad de algunos de tales proyectos que insinúan que Soacha hace parte de Bogotá, y desconocen las diferencias administrativas y físicas entre ambas.

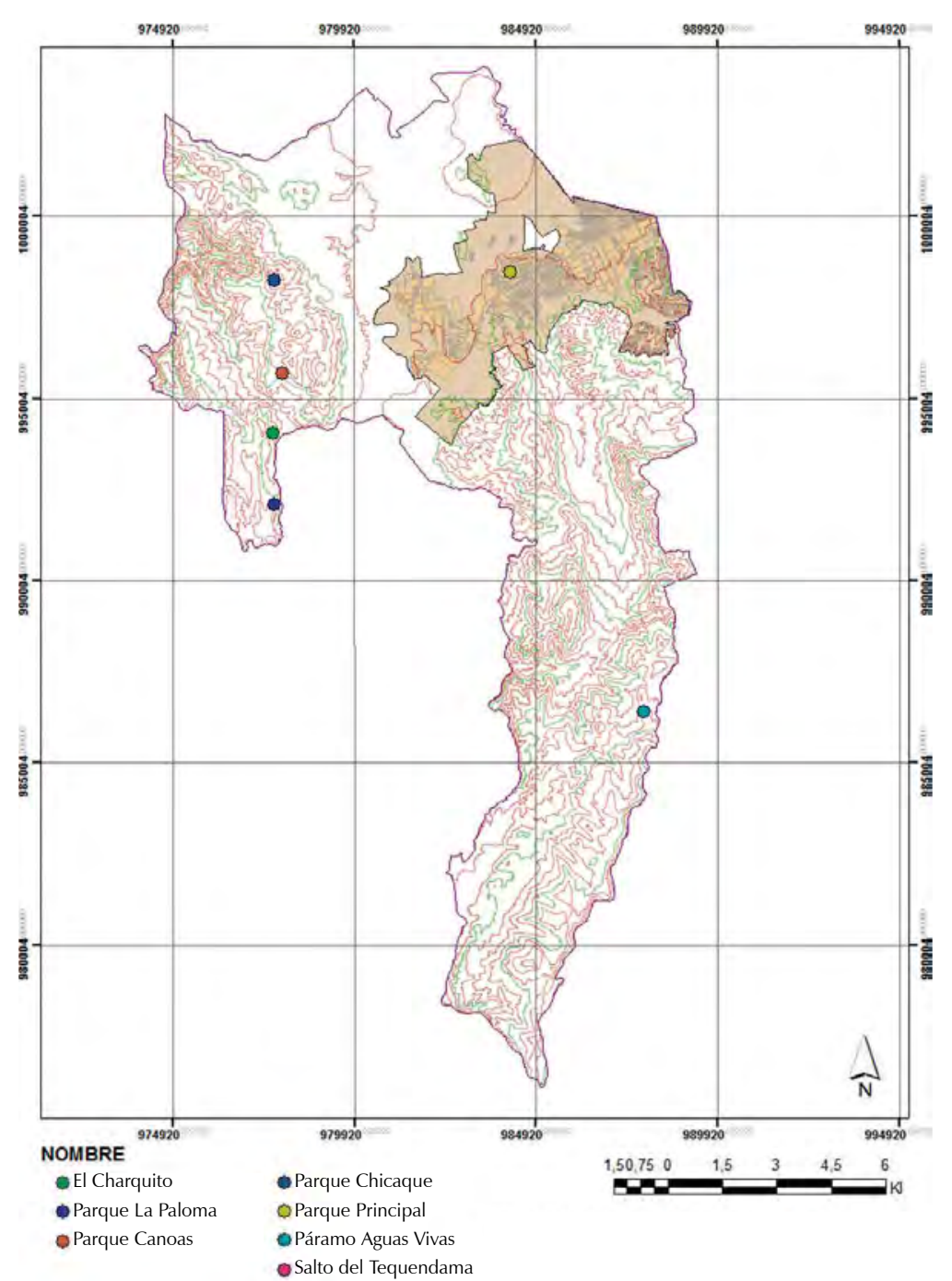

(A) Figura 24. Lugares de valor turístico reconocidos por los encuestados

Fuente: elaboración propia (2017) CC BY-NC

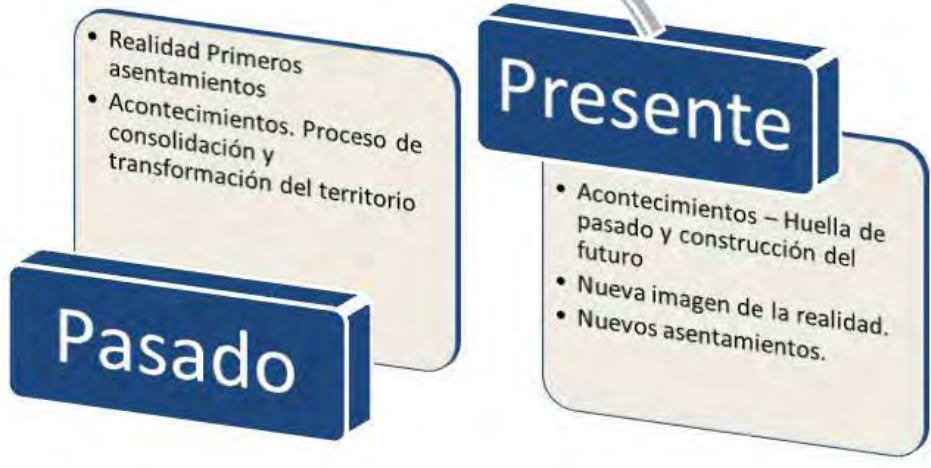

- Acontecimientos históricción. Reconocimiento - Imagen y cultural.

- Imagen ideal de ciudad asentas de futuros urbantamientos y estructuras
urbas

\section{Futuro}

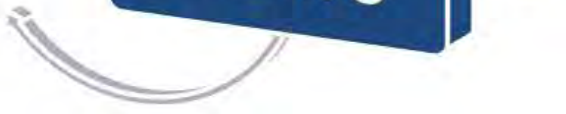

\& Figura 25. Dinámica temporal de los imaginarios colectivos Fuente: Reyes Guarnizo (2014). 
Si bien es necesario reconocer que hay un déficit de vivienda dentro del municipio, no hay una propuesta clara en el ámbito urbano frente a la articulación armónica entre los elementos urbanos y los ambientales del municipio con una mirada de identidad y apropiación al territorio.

\section{Estrategias para fortalecer la identidad y el sentido de pertenencia}

La experiencia con el grupo focal permite identificar, como primera estrategia para fortalecer la identidad y el sentido de pertenencia, los procesos de formación sobre el territorio para el cual se plantean: talleres de formación en relación con las características ambientales, históricas, arqueológicas y urbanas del municipio, junto con recorridos de reconocimiento. ${ }^{14}$

A partir de esta formación se plantea, como segunda estrategia, el diseño del espacio público de forma colaborativa y con el objetivo de que el proceso permita una identificación con el municipio, ya sea por medio de los elementos que aparecen en la ciudad o por la forma misma como se conciben, y así propiciar la gestión del proceso de trasformación o mejoramiento del sector que se vaya a intervenir, por parte de la comunidad misma.

Además de lo anterior, es necesario buscar alianzas con el ente gubernamental, dado que estas iniciativas responden a los proyectos que plantea el plan de desarrollo del municipio, a fin de tener respaldo en relación con la visibilidad del proyecto; también, como el apoyo financiero para su ejecución. Finalmente, es pertinente fortalecer las alianzas con los colectivos de jóvenes que trabajan en el municipio y articular la estrategia pedagógica a través de las dinámicas culturales.

\section{Conclusiones}

Frente a la valoración de los procesos de transformación del municipio de Soacha, se ha visto que, en algunas ocasiones, dichos procesos responden al planteamiento de políticas nacionales, situación sobre la cual la comunidad poca injerencia tiene; es decir, el área urbana del municipio de Soacha tiende a seguir creciendo. Así pues, una de las primeras conclusiones, justamente, es que se necesita generar políticas en principios de intervención de espacio público y de las zonas de sesión de las urbanizaciones, con el fin de que se generen propuestas de diseño que permitan a quienes empiezan a vivir en el municipio conocer sus características ambientales, culturales, históricas y arqueológicas.

Con el grupo focal se puede confirmar que es necesario generar estrategias pedagógicas que

14 A partir de esta experiencia se consolida la estrategia pedagógica Descubramos Nuestro Territorio, como un producto adicional con el que se trabajará con diferentes grupos en cada una de las comunas y los corregimientos del municipio. permitan a los diferentes grupos poblacionales conocer el municipio de Soacha. Frente a ese aspecto, con el apoyo de la corporación ambiental Caminando el Territorio, se realizó un instrumento de estrategia pedagógica, y se prevé una investigación de aplicación de dicha estrategia, a fin de configurar nuevos imaginarios sobre Soacha. Es evidente la riqueza acerca de lo ambiental, lo histórico, lo cultural y lo arqueológico, todo lo que se puede llegar a convertir en un potencial económico para el municipio al desarrollar propuestas que permitan a pobladores y sus visitantes conocer esta otra cara del municipio.

Los imaginarios urbanos de quienes viven o trabajan en Soacha y no conocen realmente el municipio son negativos y desfavorables para los procesos de apropiación del territorio; desafortunadamente, esta imagen se reafirma gracias a los medios de comunicación, que favorecen la estigmatización de un territorio o de un grupo poblacional.

Frente a lo anterior, es necesario recordar los elementos de la dinámica temporal de los imaginarios colectivos, que plantean una serie de pasos para la consolidación de dichos imaginarios: el primero es la creación de acontecimientos, lo cual nos invita a generar acciones que se transformen en acontecimientos para quienes viven, trabajan y visitan el municipio. El segundo es la imagen ideal de la ciudad, uno de los aspectos que se trabajarán dentro de la estrategia pedagógica, junto con el tercer elemento, que se refiere a los proyectos de futuro que permitan llegar a esa imagen ideal del municipio, a fin de consolidar nuevos imaginarios desde un trabajo de participación social contundente que redunde en el establecimiento de nuevas políticas.

Se reconoce que las formas y las estructuras urbanas de la ciudad contemporánea, así como el tipo de relaciones culturales que la sustentan, no favorecen ni posibilitan la convivencia de los valores y los comportamientos necesarios para avanzar hacia un desarrollo sostenible, aunque valores como la identidad y el sentido de pertenencia están presentes en los principios que orientan los planes de desarrollo del municipio; por tanto, es desde los procesos de gestión, desde la administración municipal y desde la participación comunitaria como se integra al ciudadano común en un proceso de cambio, búsqueda de identidad, trasformación y construcción de imaginarios: produciendo nuevas maneras de hacer uso del territorio.

El contenido social, como protagonista de la vida y la cotidianidad urbana e involucrado en el espacio, el paisaje y la cultura, busca en los espacios y en los hechos urbanos elementos de identidad que le signifiquen y tejan los lazos de apropiación y la pertenencia, a fin de conservar la memoria colectiva a través de las prácticas tradicionales y la convivencia con el ecosistema 
existente. De ahí que la estructura urbana deba ajustarse a las diversas dinámicas cotidianas para conservar la memoria y la convivencia con el ecosistema existente, en pro de un equilibrio ambiental y social en un contexto de diversidad cultural.

La visión social predominante sobre dicho ecosistema, o lo que queda de él, es la de usar este recurso natural para solucionar problemasurbanos como la expulsión de aguas residuales y desechos sólidos o la apropiación de un pedazo de tierra a bajo costo para el asentamiento, entre otros.

Esta situación hace que la comunidad no se apropie del lugar donde vive y que no sea posible construir un sentido de pertenencia e identidad, sino que se lo considere algo externo, útil solo en tanto se lo pueda aprovechar para el beneficio particular. Finalmente, es importante identificar si, de verdad, esa es la imagen que tienen todos los que viven en Soacha, dentro de cada barrio, comuna o colectivo.

\section{Referencias}

Acuerdo 18 de 2008, por medio del cual se adopta el plan de desarrollo municipal de Soacha año 2008-2011 "Soacha para vivir mejor". Concejo Municipal de Soacha. Mayo 31 de 2008.

Acuerdo 46 de 2000, por medio del cual se adopta el Plan de Ordenamiento Territorial del Municipio de Soacha. Concejo Municipal de Soacha. 27 de diciembre de 2000. Recuperado de: h t t p s : / / w w w. s c ri b d. c o m document/116162102/PIan-deOrdenamiento-Territorial-Soacha-2000

Altman, I. (1975). The environment and social behavior: Privacy, personal space, territoriality and crowding. Monterey, Ca: Brooks/Cole.

Bonilla Castro, E., \& Rodriguez Sehk, P. (1997). Más allá del dilema de los métodos. La investigación en las ciencias sociales. Bogotá: Norma.

Cámara de Comercio de Bogotá. (2005). Plan económico para la competitividad de Soacha. Bogotá: Cámara de Comercio de Bogotá.

Departamento Administrativo Nacional de Estadística (DANE). (2010). Boletín del Censo General 2005. Recuperado de: https://www.dane.gov.co/files/censo2005/ PERFIL_PDF_CG2005/25754T7T000.PDF

Departamento Nacional de Planeación. (2014). Plan Nacional de Desarrollo. Recuperado de: Planes de Desarrollo anteriores:

h t t p s : / / w w w. s c r i b d. c o m / document/315443620/PLAN-NACIONALDE-DESARROLLO-2014-2018

Departamento Nacional de Planeación. (1972). Las cuatro estrategias. Recuperado de: https://colaboracion.dnp.gov.co/CDT/PND/ Pastrana1_Prologo.pdf

Departamento Nacional de Planeación. (1983). Cambio con equidad. Plan de Desarrollo 19831986. Recuperado de:

https://colaboracion.dnp.gov.co/CDT/PND/ Betancur_Fundamentos_Plan.pdf

Departamento Nacional de Planeación. (1987). Plan de economía social (1986-1990). Recuperado de:

https://colaboracion.dnp.gov.co/CDT/PND/ Barco Prologo.pdf

Departamento Nacional de Planeación. (1991). La revolución pacífica. Plan de desarrollo económico y social 1990-1994. Recuperado de:

https://colaboracion.dnp.gov.co/CDT/PND/ Gaviria Prologo.pdf

Departamento Nacional de Planeación. (1995). El salto social (1994-1998). Recuperado de: https://colaboracion.dnp.gov.co/CDT/PND/ Samper_fundamentos_plan.pdf

Departamento Nacional de Planeación. (1998). Cambio para construir la paz (1998-2002). Recuperado de: https://colaboracion.dnp. gov.co/CDT/PND/Pastrana2 Contexto Cambio.pdf
Departamento Nacional de Planeación. (1994). Departamento Nacional de Planeación. Recuperado de: Planes de Desarrollo anteriores: https://www.dnp.gov.co/Plan-Nacional-deDesarrollo/Paginas/Planes-de-Desarrolloanteriores.aspx

Durand, G. (1964). L'imagination symbolique. París: Presses Universitaires de France.

Durand, G. (1994). El imaginario, ciencia y filosofía de la imagen. París: Hatier.

García Canclini, N. (1995). Consumidores y ciudadanos. México, D.F.: Grijalbo S.A. Recuperado de:

https://antroporecursos.files.wordpress. com/2009/03/garcia-canclini-n-1995consumidores-y-ciudadanos.pdf

García Canclini, N. (2005). Imaginarios urbanos. Buenos Aires: Editorial Universitaria.

Haesbaert, R. (1997). Des-territorializaçao e identidade: a rede "gaucha" no nordeste. Niterói: Editora da Universidade Federal Fluminense, EDUFF.

Haesbaert, R. (2002). Territórios alternativos. Niterói: Editora da Universidade Federal Fluminense, EDUFF.

Haesbaert, R. (2004a). Des-caminhos e perspectivas do territorio. En: Ribas, A.; Sposito, E.; Saquet, M. (Org.). Territórios e Desenvolvimento: Diferentes Abordagens (pp. 87-119). Paraná: Francisco Beltrão, UNIOESTE. Recuperado de: http://unbral.nuvem.ufrgs.br/base/items/ show $/ 2800$

Haesbaert, R. (2004b). O mito da desterritorialização: do "fim dos territórios" a Multiterritorialidade. Rio de Janeiro: Bertrand Brasil.

Hiernaux, D. (2007). Los imaginarios urbanos: de la teoría y los aterrizajes en los estudios urbanos. Revista Eure, 33(99), 17-30. http://dx.doi.org/10.4067/S025071612007000200003

Ley 9 de 1989, por la cual se dictan normas sobre planes de desarrollo municipal, compraventa y expropiación de bienes y se dictan otras disposiciones. Enero 11 de 1989. Congreso de Colombia. Recuperado de: https://www.alcaldiabogota.gov.co/ sisjurMantenimiento/normas/Norma1. jsp?i=1175

Lobato Correa, R. (1997) Territorialidade e Corporato: Um Exemplo. En Territòrio: Globalizagào e Fragmentagào (pp. 251-256). Sao Paulo: Editora Hucitec

Montañez, G. (2001). Introducción. Razón y pasión del espacio despacio y el territorio. En: G. Montañez. Espacio y Territorios. Razón, pasión e Imaginarios (pp. 15-32). Bogotá: Universidad Nacional de Colombia. Unibiblos.

Pérez, M. (2004). Territorio y desplazamiento. El caso de Altos de Cazucá, municipio de Soacha. Bogotá: Pontificia Universidad Javeriana.
Resolución 1687 de 2009, por medio de la cual se adopta, por motivos de utilidad pública e interés social, el Macroproyecto de Interés Social Nacional 'Ciudad Verde' en el municipio de Soacha, Cundinamarca. Diario Oficial de Colombia. 11 de septiembre de 2009.

Reyes Guarnizo, A. B. (2011). Un mito que cobra vida, la inundación del tequendama. En F. P. Fedes, Soacha el derecho a vivir bien, una herramienta para la formación y el debate. (p. 123). Bogotá: Antropos.

Reyes Guarnizo, A. B. (2014). De los imaginarios colectivos a la apropiación del territorio, un recorrido conceptual. Bitácora Urbano Territorial, 1(24), 10-17. Recuperado de: https://revistas.unal.edu.co/index.php/ bitacora/article/view/32452/html_1

Santos, M. (1991, junio diciembre). A revoluqáo tecnológica e territorio: realidades e perspectiva. Terra Livre, 9, 7-17. Recuperado de:

https://www.agb.org.br/publicacoes/index. php/terralivre/article/viewFile/101/100

Santos, M. (1997). Espacio y territorios. Razón, Pasión e Imaginarios. Barcelona: Ariel.

Schneider, S., \& Peyre, I. G. (2006). Territorio y enfoque territorial: De las referencias cognitivas a los aportes aplicados al análisis de los procesos socio rurales. En: M. Manzanal, G. Neiman, \& M. Lattuada, Desarrollo rural. Organizaciones, instituciones y territorios (pp. 71-102). Buenos Aires: Ciccus.

Souza, M. L. (1995). O território: sobre espaço e poder, autonomia e desenvolvimento. En: Castro, Iná et. al. (Orgs.). Geografia: Conceitos e Temas (pp. 77-116). Rio de Janeiro: Bertrand Brasil.

Sposito, E. S. \& Saquet, M. A., Ribas, A. (2004). Território e desenvolvimento: diferentes abordagens. Paraná: Francisco Beltrão, UNIOESTE.

Torres, E. (2010, febrero 19). La ciudad desde los imaginarios urbanos. [Entrada de blog]. La ciudad viva. Recuperado el 3 de mayo de 2012 de http://www.laciudadviva.org/blogs/?p=3569

Vergara Figueroa, A. (2001). Imaginarios: horizontes plurales. México: Escuela Nacional de Antropología e Historia.

Vidal Montana, T. \& Pol Urrutia, E. (2005). La apropiación del espacio: una propuesta teórica para comprender la vinculación entre las personas y los lugares. Anuario de Psicología, 36(3), 281-297. Recuperado de: https://www.raco.cat/index.php/An uarioPsicologia/article/view/61819 


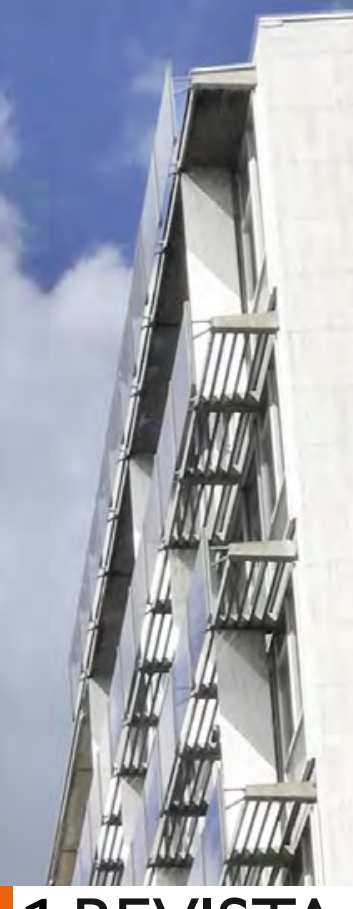

\section{Nro. 1 REVISTA DE ARQUITECTURA}
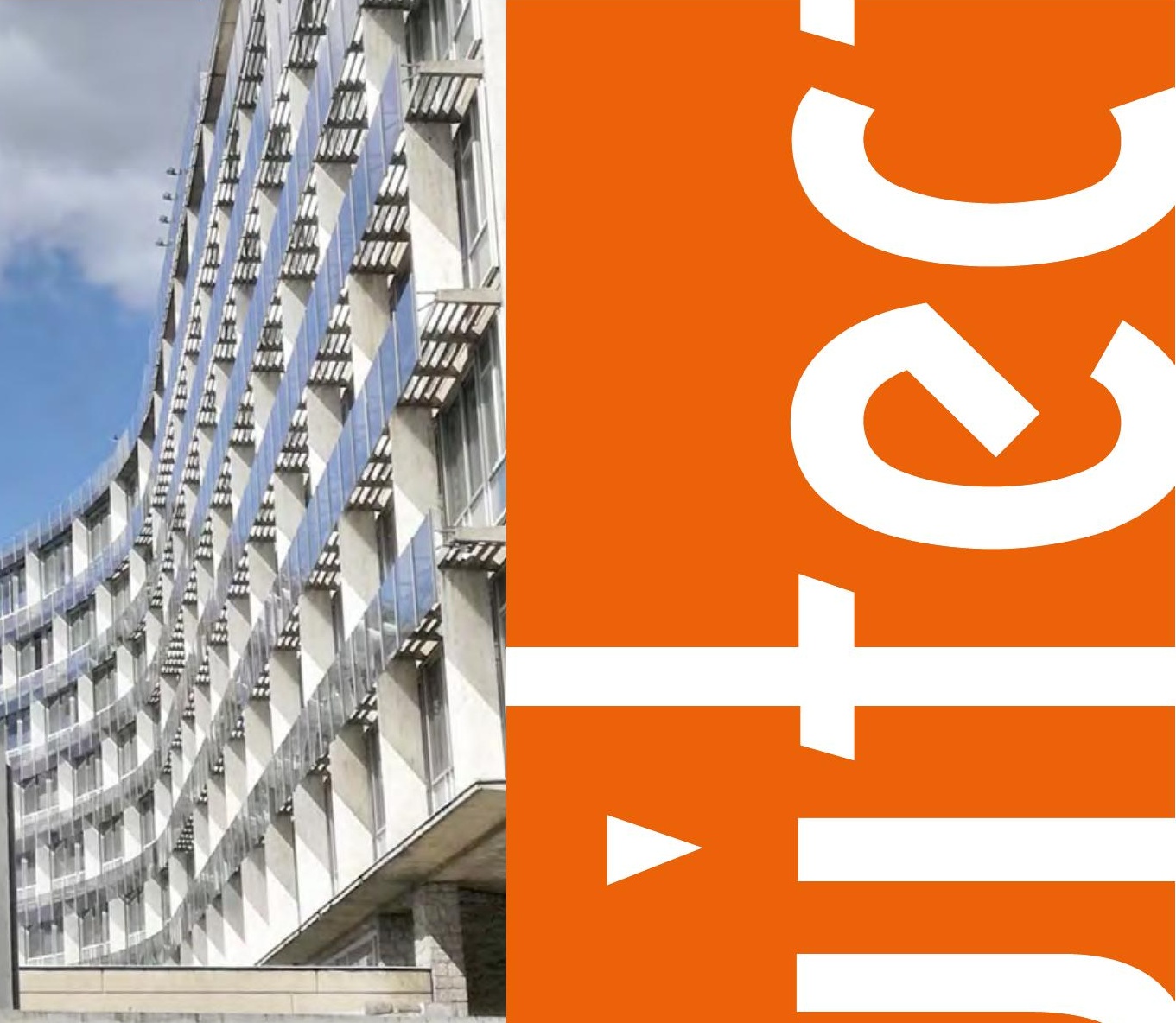

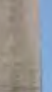

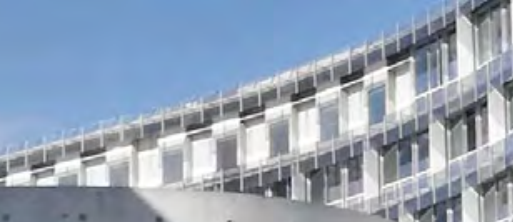

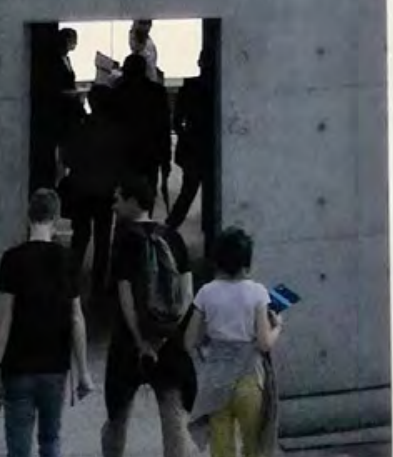

$\Phi$

- Revista de Arquitectura (Bogotá)

- Vol. 22 Nro. 12020 enero-junio

•pp. 1-188•ISSN: 1657-0308•E-ISSN: 2357-626X

- Bogotá, Colombia
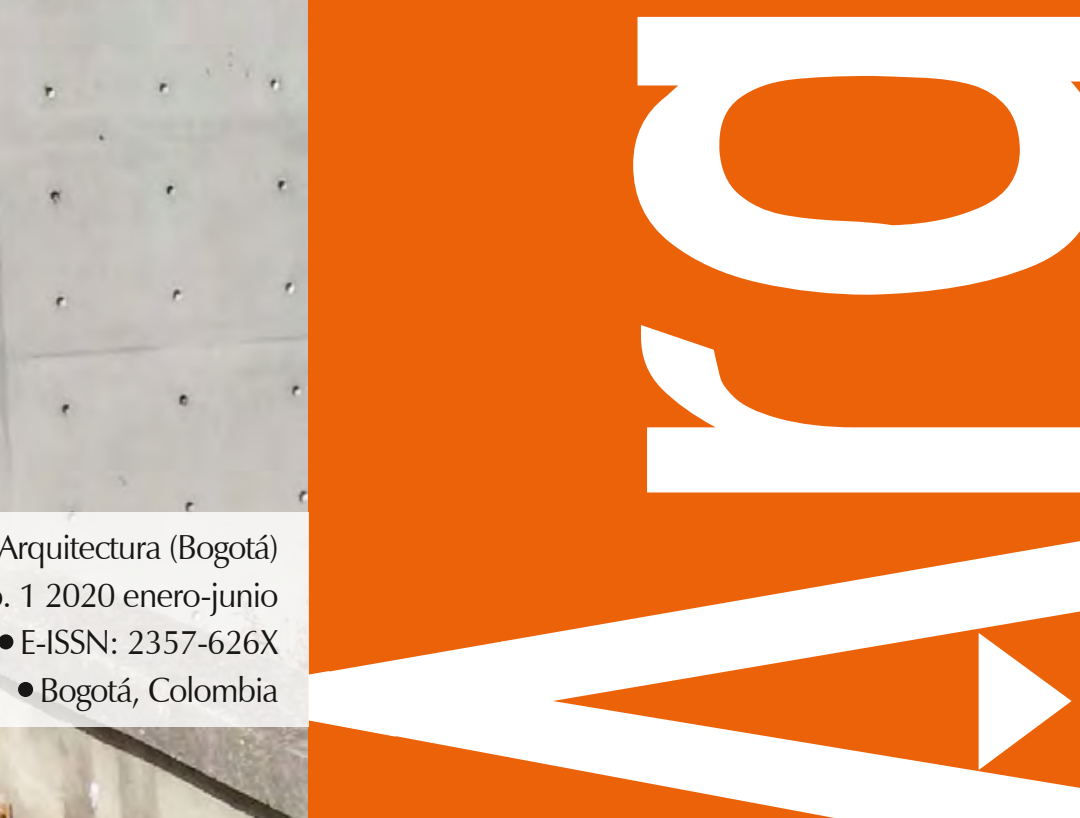


\section{Enfoque y alcance}

La Revista de Arquitectura (Bogotá) ( (ISSN 1657-0308 Impresa y E-ISSN 2357-626X en línea) es una publicación científica seriada de acceso abierto, arbitrada mediante revisión por pares (doble ciego) e indexada, en donde se publican resultados de investigación originales e inéditos.

Está dirigida a la comunidad académica y profesional de las áreas afines a la disciplina. Es editada por la Facultad de Diseño y el Centro de Investigaciones (CIFAR) de la Universidad Católica de Colombia en Bogotá (Colombia).

La principal área científica a la que se adscribe la Revisto de Arquitectura (Bogotá) según la OCDE es:

Gran área: 6. Humanidades

Área: 6.D. Arte

Disciplina: 6D07. Arquitectura y Urbanismo

También se publican artículos de las disciplinas como 2A02, Ingeniería arquitectónica; 5C03, Estudios urbanos (planificación y desarrollo); 6D07, Diseño.

Los objetivos de la Revista de Arquitectura (Bogotá) son:

- Promover la divulgación y difusión del conocimiento generado a nivel local, nacional e internacional

- Conformar un espacio para la construcción de comunidades académicas y la discusión en torno a las secciones definidas.

- Fomentar la diversidad institucional y geográfica de los autores que participan en la publicación.

- Potenciar la discusión de experiencias e intercambios científicos entre investigadores y profesionales.

- Contribuir a la visión integral de la arquitectura, por medio de la concurrencia y articulación de las secciones mediante la publicación de artículos de calidad.

- Publicar artículos originales e inéditos que han pasado por revisión de pares, para asegurar que se cumplen las normas éticas, de calidad, validez científica, editorial e investigativa.

- Fomentar la divulgación de las investigaciones y actividades desarrolladas en la Universidad Católica de Colombia.
Palabras clave de la Revista de Arquitectura (Bogotá): arquitectura, diseño, educación arquitectónica, proyecto y construcción, urbanismo.

Idiomas de publicación: español, inglés, portugués y francés. Título abreviado: Rev. Arquit.

\section{Titulo corto: RevArq}

\section{Políticas de sección}

La revista se estructura en tres secciones correspondientes a las líneas de investigación activas y aprobadas por la institución, y dos complementarias, que presentan dinámicas propias de la Facultad de Diseño y las publicaciones relacionadas con la disciplina.

Cultura y espacio urbano. En esta sección se publican los artículos que se refieren a fenómenos sociales en relación con el espacio urbano, atendiendo aspectos de la historia, el patrimonio cultural y físico, y la estructura formal de las ciudades y el territorio.

Proyecto arquitectónico y urbano. En esta sección se presentan artículos sobre el concepto de proyecto, entendido como elemento que define y orienta las condiciones proyectuales que devienen en los hechos arquitectónicos o urbanos, y la forma como estos se convierten en un proceso de investigación y nuevo de conocimiento. También se presentan proyectos que sean resultados de investigación, los cuales se validan por medio de la ejecución y transformación en obra construida del proceso investigativo. También se contempla la publicación de investigaciones relacionadas con la pedagogía y didáctica de la arquitectura, el urbanismo y el diseño.

Tecnología, medioambiente y sostenibilidad. En esta sección se presentan artículos acerca de sistemas estructurales, materiales y procesos constructivos, medioambiente y gestión, relacionados con los entornos social-cultural, ecológico y económico.

Desde la Facultad. En esta sección se publican artículos generados en la Facultad de Diseño, relacionados con las actividades de docencia, extensión, formación en investigación o internacionalización, las cuales son reflejo de la dinámica y de las actividades realizadas por docentes, estudiantes y egresados; esta sección no puede superar el $20 \%$ del contenido.

Textos. En esta sección se publican reseñas, traducciones y memorias de eventos relacionados con las publicaciones en Arquitectura y Urbanismo.
A Frecuencia de publicación

Desde 1999 y hasta el 2015, la Revista de Arquitectura (Bogotá) publicó un volumen al año, a partir del 2016 se publicarán dos números por año en periodo anticipado, enero-junio y julio-diciembre, pero también maneja la publicación anticipada en línea de los artículos aceptados (versión Post-print del autor).

La Revista de Arquitectura (Bogotá) se divulga mediante versiones digitales (PDF, HTML, EPUB, XML) e impresascon un tiraje de 700 ejemplares, los tiempos de producción de estas versiones dependerán de los cronogramas establecidos por la editorial.

Los tiempos de recepción-revisión-aceptación pueden tardar entre seis y doce meses dependiendo del flujo editorial de cada sección y del proceso de revisión y edición adelantado.

Con el usuario y contraseña asignados, los autores pueden ingresar a la plataforma de gestión editorial y verificar el estado de revisión, edición o publicación del artículo.
A Canje

La Revista de Arquitectura (Bogotá) está interesada en establecer canje con publicaciones académicas, profesionales o científicas del área de Arquitectura y Urbanismo, como medio de reconocimiento y discusión de la producción científica en el campo de acción de la publicación.

\section{Mecanismo}

Para establecer canje por favor descargar, diligenciar y enviar el formato: RevArq FP20 Canjes
Universidad Católica de Colombia (2020, enero-junio). Revista de Arquitectura (Bogotá), 22(I) I-I88. Doi: 10.14718

ISSN: $1657-0308$ E-ISSN: 2357-626X

Especificaciones:

Formato: $34 \times 24 \mathrm{~cm}$

Papel: Mate $115 \mathrm{~g}$

Tintas: Negro y policromía
A Contacto

Dirección postal:

Avenida Caracas No. 46-72

Universidad Católica de Colombia

Bogotá D.C.(Colombia)

Código postal: 111311

Facultad de Diseño Centro de Investigaciones (CIFAR). Sede El Claustro. Bloque "L", 4 piso Diag. 46A No. 15b-10 Editor, Arq. César Eligio-Triana

Teléfonos:

+57 (1) $3277300-3277333$

Ext. $3109 ; 3112$ o 5146

Fax: +57 (1) 2858895
Correo electrónico:

revistadearquitectura@ucatolica.edu.co cifar@ucatolica.edu.co

Página WEB: www.ucatolica.edu.co vínculo Revistas científicas

http://publicaciones.ucatolica.edu.co revistas-cientificas http://editorial.ucatolica.edu.co/ojsucatolica/revistas ucatolica/index.php/RevArq 
